Research Article

\title{
Identifying Chinese Medicine Patterns of Tension-Type Headache and Understanding Its Subgroups
}

\author{
Xinyu Hao, ${ }^{1,2}$ Fanrong Liang, ${ }^{1,2}$ Linpeng Wang, ${ }^{3}$ Kenneth Mark Greenwood, ${ }^{4}$ \\ Charlie Changli Xue, ${ }^{5}$ Zhen Zheng $\mathbb{D},{ }^{5}$ and Ying Li $\mathbb{1}^{2,6}$ \\ ${ }^{1}$ Acupuncture and Tuina School, Chengdu University of Traditional Chinese Medicine, Chengdu 610075, China \\ ${ }^{2}$ Acupuncture and Chronobiology Key Laboratory of Sichuan Province, Chengdu 610075, China \\ ${ }^{3}$ Department of Acupuncture, Beijing Traditional Chinese Medical Hospital, Capital Medical University, Beijing 100010, China \\ ${ }^{4}$ School of Social Science, University of Sunshine Coast, Queensland QLD4558, Australia \\ ${ }^{5}$ School of Health and Biomedical Sciences, RMIT University, Melbourne VIC3083, Australia \\ ${ }^{6}$ Graduate School, Chengdu University of Traditional Chinese Medicine, Chengdu 610075, China
}

Correspondence should be addressed to Zhen Zheng; zhen.zheng@rmit.edu.au and Ying Li; liying@cdutcm.edu.cn

Received 8 February 2021; Revised 13 July 2021; Accepted 3 August 2021; Published 23 September 2021

Academic Editor: Hongcai Shang

Copyright (c) 2021 Xinyu Hao et al. This is an open access article distributed under the Creative Commons Attribution License, which permits unrestricted use, distribution, and reproduction in any medium, provided the original work is properly cited.

\begin{abstract}
Tension-type headache (TTH) is common among adults. Individualized management strategies are limited due to lack of understanding of subtypes of TTH. Chinese medicine (CM) uses the pattern differentiation approach to subtype all health conditions. There is, however, a lack of evidence-based information on CM patterns of TTH. This study aimed to identity common CM patterns of TTH. TTH sufferers were invited for a survey, consisting of a validated Chinese Medicine Headache Questionnaire (CMHQ), Migraine Disability Assessment Test, and Perceived Stress Scale. The CMHQ consisted of information about headache, aggravating and relieving factors, and accompanying symptoms. Principal component analysis was used for factor extraction and TwoStep cluster analyses for identifying clusters. ANOVA was used to compare cluster groups with disability and stress. In total, 170 eligible participants took part in the survey. The commonest headache features were continuous pain (64\%); fixed location (74\%); aggravated by overwork (74\%), stress (74\%), or mental strain (70\%); and relieved by sleeping (78\%). The commonest nonpain symptoms were fatigue (71\%) and neck stiffness (70\%). Four clusters, differing in their key signs and symptoms, could be assigned to three different CM patterns including ascendant hyperactivity of liver yang (cluster 1), dual qi and blood deficiency (cluster 2), liver depression forming fire (cluster 3), and an unlabelled group (cluster 4). Additionally, over $75 \%$ participants in clusters 1 and 2 have episodic TTH, over one-third participants in cluster 3 have chronic TTH, and a majority of participants in cluster 4 have infrequent TTH. The three patterns identified also differed in levels of disability and some elements of coping as measured with PSS. The three CM patterns identified are common clinical presentations of TTH. The new information will contribute to further understanding of the subtypes of TTH and guide the development of targeted intervention combinations for clinical practice and research.
\end{abstract}

\section{Introduction}

Tension-type headache (TTH), described as a dull, pressing, or tight quality [1], is found to be the second most prevalent chronic disorders in the world [2]. TTH is regarded as a featureless headache, as most TTH sufferers have no associated symptoms when compared with other type of headaches. Due to its nonspecific and lacking specific and distinguishing feature [3], diagnosis of TTH is, therefore, largely based on negative features $[3,4]$ and by excluding symptoms, syndromes, and organ diseases mimicking other primary or secondary headache [5]. However, the treatment strategies for TTH remain unspecific as its underlying mechanisms are unknown $[3,6,7]$. In addition, it is well known that people with TTH have different headache features [8-11], yet there is no standard way to subtype TTH, except for categorizing into infrequent, episodic (ETTH), and chronic TTH (CTTH) based on the frequency of 
headache within four weeks [1]. Such an approach does not lead to the development of effective, individualised treatment strategy [5].

Trigger factors could worsen TTH [12, 13]. Hence, identification of triggers and coping with these factors may be of values [14]. One hospital-based study confirmed that emotional stress was the major trigger factor of TTH, as outlined in other studies $[8,15]$. Depression and anxiety levels in TTH sufferers have also been observed to be higher than headache-free controls $[16,17]$. In addition, some triggers that are typically specific to migraine may also precipitate TTH [5], including a lack of sleep, fatigue, missing meals [18], menstruation, weather changes, relaxation after stress, exposure to bright lights, strong odors and loud noises, and ingestion of alcoholic beverages [18-20]. Presence of triggers for TTH is largely relied on patients' self-report, but has not been tested systematically [13].

Chinese medicine $(\mathrm{CM})$, which has a long history of treating headaches, is viewed as "personalized medicine" as CM differential diagnostic approach guides the tailored treatment for each individual [21]. Given that TTH is not a diagnosis in CM, recognition and treatment of TTH must be based on the CM classification and common patterns of general headache. CM understands that the causes of most headaches are disorders of Qi and blood or lack of nourishment of the channels and collaterals [22]. The guiding principle of $\mathrm{CM}$ headache treatment is to enhance and strengthen any deficiency identified or eliminate and dispel the excessive pathogens, which vary from person to person. It is through addressing different forms of deficiency or excess that CM treatment is tailored to individuals.

Acupuncture, a key treatment modality of $\mathrm{CM}$, has been reported to be effective for pain management $[23,24]$. Acupuncture has been recommended as a prophylactic treatment for chronic TTH due to its effectiveness and safety profile $[25,26]$. It is a valuable nonpharmacological option for patients suffering from frequent episodic or chronic TTH $[27,28]$. In acupuncture treatment, each health condition is subdivided into a few common patterns based on signs and symptoms. Those patterns are important as they guide the selection of the supposed optimal individualised acupuncture protocol. Nevertheless, there is a lack of CM criteria for TTH patterns, which are important as they guide the determination of the optimal acupuncture protocol. Identifying CM patterns involves a complicated process of synthesising and analysing clinical symptoms and signs of the patient's condition to determine the location, cause, and nature of the condition [29]. Diagnosis of TTH largely relies on textbook information or expert opinion but not based on research evidence. Over the past several years, published CM studies specific to TTH in China proposed different TTH patterns based on clinical experiences and observations with some overlaps among them. Those include eleven (11) patterns of ascendant hyperactivity of liver yang, kidney deficiency, spleen deficiency, liver qi stagnation, stagnated gall bladder qi with disturbing phlegm, liver fire ascending, cold congealing in the jueyin meridian, static blood blocking collaterals, deficiency of heart and spleen, kidney yin deficiency, and deficiency of both liver yin and kidney yin [30].
Consequently, variations in the diagnosis of TTH among practitioners are common [31]. Studies have shown that it is possible to standardize and validate patterns using objective methods and evidence-based approaches [21, 32-37]. Cluster analysis has been recognized as a suitable technique to identify homogeneous subgroups for identifying $\mathrm{CM}$ patterns of diseases [38-40].

The aims of this study were (1) to explore CM patterns of TTH based on data collected using a validated Chinese Medicine Headache Questionnaire (CMHQ); and (2) to explore if identified CM patterns differed on information collected in modern TTH research and practice, including headache features, severity of headache-related disability assessed with Migraine Disability Assessment Test (MIDAS), and number of comorbidities, psychological profiles, such as anxiety, depression, and self-perceived level of stress. Findings of this research will lend a hand to understanding of subtypes of TTH.

\section{Methods}

2.1. Design. A bilingual cross-sectional survey was conducted from February 2011 to June 2012. A paper-based survey and an online survey were delivered in parallel. The online survey was performed via the SurveyMonkey ${ }^{\circledR}$ platform, whereas the paper-based survey was administrated at three sites: Melbourne, Beijing, and Chengdu. The Australian sample was from a clinical trial conducted from 2008-2012 entitled "Combined therapy of electroacupuncture and cognitive behavioural therapy for tensiontype headache: a randomised controlled trial" (ANZCTR: ACTRN12608000239369) in Melbourne and from online survey. All Chinese samples were collected from two Chinese sites and through online. The two Chinese sites were of Beijing Hospital of Traditional Chinese Medicine (TCM) Affiliated to Capital Medical University and Affiliated Hospital of Chengdu University of TCM.

2.2. Ethics. The survey protocol was reviewed, assessed, and approved by the College Human Ethics Advisory Network of the College of Science Engineering and Health (CHEAN), RMIT University (BESHAPP10-11 HAO). The other two collaboration sites of Beijing and Chengdu were granted permission by the Department of Science Research of Beijing TCM Hospital and for the Chengdu site, by the Department of Science and Technology, Chengdu University of TCM, respectively. Those approvals were endorsed by CHEAN, RMIT.

2.3. Recruiting Criteria. Potential headache sufferers, aged from 18 to 65 years old, were eligible to participate if they were able to read English or Chinese; met the International Headache Society TTH diagnostic (ICHD-II) criteria of TTH or probable TTH [41]; and had one day or more of TTH attacks per month for at least one year. Exclusion criteria were TTH onset after 50 years old as those headaches are more likely to be secondary headache [42]; had more than 4 migraine attacks without aura per month, as 
increased attacks of migraines should be classified under migraine, rather than TTH according to ICHD-II [41]; had any migraine attack with aura per month; had been hospitalized because of the head or neck injury; or had migraine attacks which were not able to be distinguished from TTH.

2.4. Measurements. Demographic characteristics of the participants collected from this survey included gender, age, ethnicity, marital status, and education. Each of the listed instruments included in the survey was available in both English and Chinese versions.

Chinese Medicine Headache Questionnaire (CMHQ): the CMHQ is a symptom-based data collection tool consisting of a total 193 items which are grouped into three broad categories of pain description, aggravating and relieving factors, and accompanying symptoms. It has been used to assist CM pattern identification for headache disorders and found to be reliable and valid in capturing essential clinical indicators for making a CM diagnosis [30]. Responses to each item presented were on a 5-point Likert scale rating from 0 to 4 indicating never, seldom, sometimes, often and almost always (Appendix A).

\subsubsection{Migraine Disability Assessment (MIDAS)} Questionnaire. The MIDAS was initially designed for the migraine population to evaluate the severity of migraine. Studies have shown it is also valid and reliable in evaluating disability associated with TTH [43-48].

2.4.2. Perceived Stress Scale (PSS). The PSS is a widely used instrument in measuring nonspecific psychological stress. Its 10 -item version is among the most widely used tool to measure global perceived stress in relation to the healthrelated outcomes $[49,50]$.

2.4.3. Comorbidity Checklist. A comorbidity checklist was used to assess both somatic and mental comorbidity of TTH. Development of the checklist was based on the Cumulative Illness Rating Scale (CIRS) [51] and the World Mental Health Composite International Diagnostic Interview (WMH-CIDI) [52]. The items in this checklist were reformatted in a coherent manner to detect both somatic comorbidity and the mental comorbidity.

2.5. Data Analysis. SPSS 18.0 was used for data analysis. A $P$ value $<0.05$ was considered to be statistically significant. Chi-squared tests were used to examine the difference in categorical outcomes. Factor analysis and cluster analysis were conjunctively applied to obtain effective clusters and identify meaningful CM patterns for TTH. Specifically, the principal component analysis (PCA) was used for factor extraction in condensing respondents' responses to diagnostic information obtained from CMHQ items, whereas the TwoStep cluster algorithm was then used for grouping these identified factors into clusters for further evaluation $[53,54]$. For PCA factor extraction, a cutoff value of 0.5 on a coefficient ("factor loading”) was adopted [55]. To determine if an identified factor was included in pattern identification based on the results from TwoStep cluster analyses, a cutoff value of 0.4 on clusters' mean scores was used. ANOVA was used to assess the cluster difference in MIDAS grades and in PSS levels. Chi-squared tests and ANOVA were employed to compare the characteristics of the resulting clusters, which enables further examination of the group differences among the CM pattern types, in MIDAS grades, and in PSS levels of the participants. Multiple comparisons were performed to compare group means via post hoc tests with Bonferroni correction when significant differences were observed in means across groups. For missing data handling, both case deletion and imputation methods were applied. Cases having more than $30 \%$ missing values within the total 193 items in CMHQ were deleted from the dataset, whereas cases having less than $30 \%$ missing values were remedied via the expectation-maximization algorithm [55].

Evaluation and interpretation of data for pattern identification had four sequential steps (Figure 1). The first step was to reduce the items of CMHQ into smaller datasets using factor analysis; the second step was to assess the factors extracted and to label those factors in a clinical meaningful manner; the third step was to group (clinical meaningful) factors into clusters using cluster analysis; the final step was the identification of TTH patterns, that is, to label the clusters into clinically meaningful CM patterns. Sixteen teaching and research staff across universities and hospitals with their professional backgrounds covering CM, acupuncture, modern medicine, statistics, etc., were invited to provide their experts' opinions in the $2^{\text {nd }}$ and $3^{\text {rd }}$ steps to ensure that the labels assigned to factors and clusters were of clinical relevance and significance. Only the labels that reached $70 \%$ agreement among 16 evaluators were retained.

\section{Results}

From February 2011 to June 2012, a total of 565 respondents took part in the survey and 497 completed it. 170 participants were eligible and included for data analysis. Figure 2 illustrates the participant selection process. Among them, $70.6 \%$ were female and $29.4 \%$ were male $(\mathrm{F}: \mathrm{M}=2.1: 1)$. The average age was 38 years $(\mathrm{SD}=12)$. Defined by headache days per month, a majority (63\%) of the included participants suffered from ETTH, whereas $23 \%$ and $14 \%$ were of CTTH and infrequent subtypes, respectively. Sociodemographic characteristics including ethnicity, marital status, and education are shown in Table 1, which indicates a majority of participants were female with a higher level of education degree in the age range of 20 to 40 .

According to the CMHQ, the key features of the headaches were pain with a fixed location (74\%), of continuous (66.7\%) and intermittent (52.7\%) nature, with tight (35.3\%), heavy (34.1\%), and pulsating (34.1\%) sensations, and affecting the neck (61.3\%) and eyes (57.2\%). Overwork $(74.1 \%)$, stress $(73.6 \%)$, mental strain $(70 \%)$, being tired (68.1\%), lack of sleep (68.1\%), anger or irritability $(65.8 \%)$, anxiety (excessive worry) (65.5\%) nervousness (56.3\%), and muscular strain (muscle tightness) $(53.1 \%)$ were identified as 


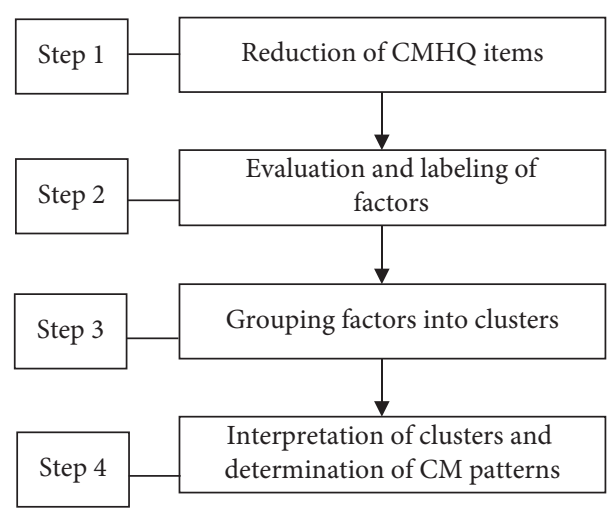

Figure 1: Process of CM pattern identification.

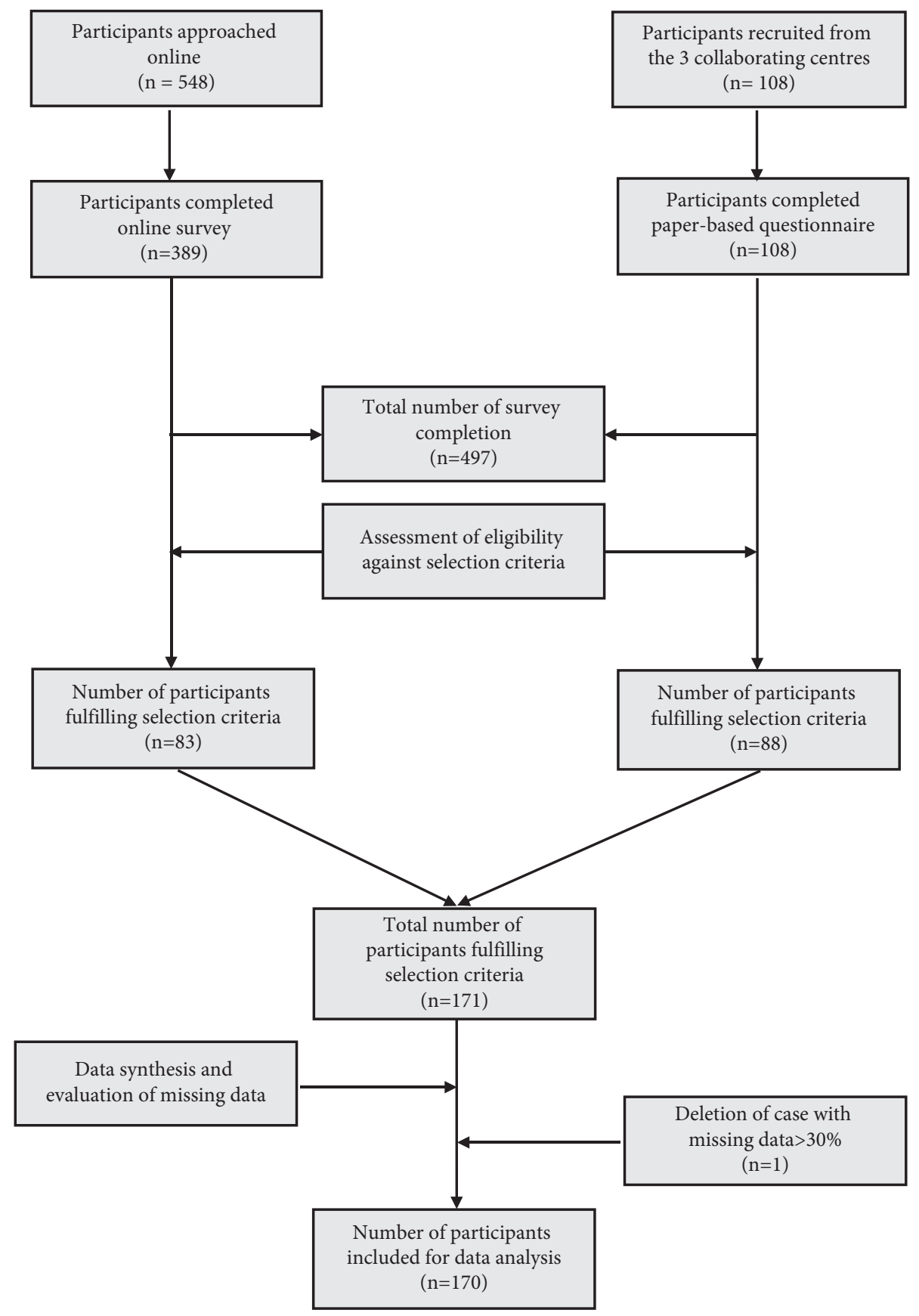

FIGURE 2: Flow chart of participant recruitment and screening process. 
TABLE 1: Sociodemographic characteristics of the included participants.

\begin{tabular}{|c|c|c|}
\hline & Frequency $(n)$ & Percent \\
\hline \multicolumn{3}{|l|}{ Gender $(n=170)$} \\
\hline Women & 120 & 70.6 \\
\hline Men & 50 & 29.4 \\
\hline \multicolumn{3}{|l|}{ Age range $(n=166)$} \\
\hline $20-29$ & 55 & 33.1 \\
\hline $30-39$ & 44 & 26.5 \\
\hline $40-49$ & 31 & 18.7 \\
\hline $50-59$ & 26 & 15.7 \\
\hline $60+$ & 10 & 6.0 \\
\hline \multicolumn{3}{|l|}{ Marital status $(n=165)$} \\
\hline Single & 64 & 38.8 \\
\hline Married & 77 & 46.7 \\
\hline Partnered & 9 & 5.5 \\
\hline Divorced & 13 & 7.9 \\
\hline Separated & 2 & 1.2 \\
\hline \multicolumn{3}{|l|}{ Ethnicity distribution $(n=164)$} \\
\hline Asian & 85 & 51.8 \\
\hline Oceanian & 45 & 27.4 \\
\hline European & 25 & 15.2 \\
\hline Arab & 1 & .6 \\
\hline Had $>1$ ethnicity & 8 & 4.9 \\
\hline \multicolumn{3}{|l|}{ Level of education $(n=164)$} \\
\hline Postgraduate degree level & 40 & 24.4 \\
\hline Graduate diploma and graduate certificate level & 8 & 4.9 \\
\hline Bachelor degree level & 72 & 43.9 \\
\hline Advanced diploma and diploma level & 18 & 11.0 \\
\hline TAFE level & 10 & 6.1 \\
\hline Secondary education & 14 & 8.5 \\
\hline Primary education & 2 & 1.2 \\
\hline
\end{tabular}

Note: designing of the sociodemographic categories were referenced from the Australian Bureau of Statistics website (http://www.abs.gov.au).

the commonest aggravating factors of headache, whereas sleeping $(77.7 \%)$, medication $(62.7 \%)$, lying down $(62.4 \%)$, pressing on the pain area $(62.1 \%)$, and massage (50.9\%) were the commonest relieving factors of the headaches. Apart from headaches, neck (60\%), shoulder (45.3\%), and lower back $(35.3 \%)$ were the most common painful areas. Of the female-related items, bright red-coloured menstrual blood (50.5\%), dark-coloured menstrual blood (62.4\%), headache before period (51.6\%), and abdominal pain during periods $(52.7 \%)$ were common referred items. Overall, the most common accompanying symptoms were fatigue $(71.3 \%)$, neck stiffness (70\%), and neck pain (60\%).

3.1. TTH Pattern Identification. The exploratory analytic methods of factor analysis and cluster analysis were conjointly used given the relatively large number of CMHQ items. Firstly, PCA was used to extract factors on each part of CMHQ separately. Based on CM theory, only 41 clinical meaningful factors, including 12 factors from CMHQ part 1 , 13 from part 2, and 16 from part 3, were labelled and retained for TTH pattern identification (Appendix B and C). Secondly, using the TwoStep cluster analysis, four distinct cluster groups were identified. Lastly, experts analysed the clinical characteristics of each cluster and labelled them as ascendant hyperactivity of liver yang (cluster 1), dual qi and blood deficiency (cluster 2), liver depression forming fire (cluster 3), and an unlabelled group (cluster 4) (Table 2). The first three are common patterns of headache presented in CM clinical practice.

3.2. Cluster Comparisons. Table 3 summarizes the characteristics of participants according to the four clusters. The four clusters differed in the aspects of demographic characteristics, stress levels, pain intensity (indicated by MIDAS item B), disability grades (indicated by MIDAS), and TTH subtypes. There were no cluster differences in gender, marital status, or education level. There was statistical age difference among the clusters $(P<0.001)$. Participants in cluster 1 were older than those in clusters 3 and 4; however, those in cluster 2 were older than those in cluster 4 . Statistically significant cluster differences were also found in ethnicity distribution. Over three quarters of participants in clusters 3 and 4 were of Asian origin, but over three quarters of those in clusters 1 and 2 were of non-Asian (Oceania and European) origin.

More than half of the participants were suffering from frequency TTH in all clusters. Cluster 1 had more infrequent ETTH headache than clusters $1-3$, and cluster 3 had more CTTH than the other three clusters $(P<0.001)$. ANOVA results indicated no cluster differences in the overall MIDAS 
TABLE 2: Summary of cluster characteristics according to the CMHQ data.

\begin{tabular}{|c|c|c|c|c|c|}
\hline & Cluster $1(n=46)$ & \multicolumn{2}{|l|}{ Cluster $2(n=34)$} & Cluster $3(n=46)$ & Cluster $4(n=44)$ \\
\hline $\begin{array}{l}\text { Location and } \\
\text { quality }\end{array}$ & $\begin{array}{l}\text { (i) Forehead; Back of the } \\
\text { head; Top of the head } \\
\text { (ii) Pain quality: Throbbing; } \\
\text { Pulsating; Pounding; Tight; } \\
\text { A "band-like" sensation }\end{array}$ & \multicolumn{2}{|c|}{$\begin{array}{l}\text { (i) Forehead, Back of the head, Top of the } \\
\text { head; Both side of the head } \\
\text { (ii) Pain quality: Throbbing; Pulsating; } \\
\text { Pounding } \\
\text { (iii) Worse in the morning; Worse at night; } \\
\text { All day }\end{array}$} & $\begin{array}{l}\text { Whole head; No } \\
\text { particular location }\end{array}$ & $\begin{array}{l}\text { Explosive; Not } \\
\text { dull; Sharp; } \\
\text { Piercing }\end{array}$ \\
\hline $\begin{array}{l}\text { Aggravating and } \\
\text { relieving factors }\end{array}$ & $\begin{array}{l}\text { Aggravating by } \\
\text { Dehydration; } \\
\text { Hunger; } \\
\text { Chocolate; } \\
\text { Muscular strain (muscle } \\
\text { tightness); } \\
\text { Poor posture in sitting, } \\
\text { standing or sleeping; } \\
\text { Teeth grinding }\end{array}$ & $\begin{array}{l}\text { Aggravating by } \\
\text { Change of weather; } \\
\text { Change in temperature; } \\
\text { Hot weather; Cold } \\
\text { weather; Dehydration; } \\
\text { Hunger; Chocolate }\end{array}$ & $\begin{array}{l}\text { Relieving by } \\
\text { Exercise; } \\
\text { Massage; } \\
\text { Pressing the pain } \\
\text { area; Warmth } \\
\text { Coldness; } \\
\text { Medication; } \\
\text { Eating }\end{array}$ & $\begin{array}{l}\text { Aggravating by } \\
\text { Stress; Nervousness } \\
\text { Irritability } \\
\text { Excessive worry; } \\
\text { Depression } \\
\text { Tension or conflict- } \\
\text { related }\end{array}$ & $\begin{array}{l}\text { Aggravating by } \\
\text { Windy days; } \\
\text { Damp weather/ } \\
\text { Humid weather; } \\
\text { Rainy days }\end{array}$ \\
\hline $\begin{array}{l}\text { Accompanying } \\
\text { symptoms }\end{array}$ & $\begin{array}{l}\text { Sensitivity to light (or to } \\
\text { bright lights); } \\
\text { Sensitivity to sound }\end{array}$ & $\begin{array}{l}\text { "Pins and needles" or nu } \\
\text { hands and feet; Faintnes } \\
\text { Watery bowel motion; L }\end{array}$ & $\begin{array}{l}\text { ambness in the } \\
\text { s; Dizziness; } \\
\text { oose bowel motion }\end{array}$ & $\begin{array}{l}\text { Dry mouth; Thirst; } \\
\text { Bitter taste in the } \\
\text { mouth }\end{array}$ & $\begin{array}{l}\text { Belching; } \\
\text { Bloating/ } \\
\text { Flatulence; } \\
\text { Indigestion; } \\
\text { Fear of being hot }\end{array}$ \\
\hline
\end{tabular}

TABle 3: Cluster comparisons of demographic data, TTH subtypes, MIDAS, PSS, and CIRS items.

\begin{tabular}{|c|c|c|c|c|c|c|c|c|c|}
\hline & \multicolumn{4}{|c|}{ TTH clusters } & \multirow{2}{*}{$\begin{array}{c}\text { Total } \\
(n) \\
170\end{array}$} & \multirow{2}{*}{$\begin{array}{c}\text { Missing } \\
\text { value }(n)\end{array}$} & \multirow{2}{*}{$\begin{array}{c}P \text { value }^{\dagger} \\
\text { Chi-square }\end{array}$} & \multirow{2}{*}{$\begin{array}{l}P \text { value }{ }^{\dagger} \\
\text { ANOVA }\end{array}$} \\
\hline & & C1 (46) & C2 (34) & C3 (46) & C4 (44) & & & & \\
\hline $\begin{array}{l}\text { Age }(\text { mean } \pm S D) \\
(n)\end{array}$ & & $\begin{array}{c}45 \pm 12 \\
44\end{array}$ & $\begin{array}{c}39 \pm 11 \\
33\end{array}$ & $\begin{array}{c}37 \pm 12 \\
37\end{array}$ & $\begin{array}{c}30 \pm 9 \\
29 \\
\end{array}$ & 143 & 27 & N/A & $\leq 0.001^{* 05}$ \\
\hline Gender $(n)$ & $\begin{array}{l}\mathrm{F} \\
\mathrm{M}\end{array}$ & $\begin{array}{l}35 \\
11\end{array}$ & $\begin{array}{c}27 \\
7\end{array}$ & $\begin{array}{l}30 \\
16\end{array}$ & $\begin{array}{l}28 \\
16\end{array}$ & $\begin{array}{c}120 \\
50\end{array}$ & 0 & .307 & N/A \\
\hline Age range $(n)$ & $\begin{array}{c}20-29 \\
30-39 \\
40-49 \\
50-59 \\
60+ \\
\end{array}$ & $\begin{array}{c}6 \\
10 \\
10 \\
14 \\
5 \\
\end{array}$ & $\begin{array}{c}8 \\
12 \\
8 \\
4 \\
2 \\
\end{array}$ & $\begin{array}{c}17 \\
10 \\
6 \\
8 \\
2 \\
\end{array}$ & $\begin{array}{c}24 \\
12 \\
7 \\
0 \\
1\end{array}$ & $\begin{array}{l}55 \\
44 \\
31 \\
26 \\
10\end{array}$ & 4 & $\mathbf{0 . 0 0 1} * 0125$ & N/A \\
\hline Marriage status $(n)$ & $\begin{array}{c}\text { Single } \\
\text { Married } \\
\text { Partnered } \\
\text { Divorced } \\
\text { Separated } \\
\end{array}$ & $\begin{array}{c}13 \\
22 \\
3 \\
6 \\
0\end{array}$ & $\begin{array}{c}10 \\
15 \\
4 \\
4 \\
1\end{array}$ & $\begin{array}{c}16 \\
25 \\
0 \\
1 \\
0\end{array}$ & $\begin{array}{c}25 \\
14 \\
2 \\
2 \\
1\end{array}$ & $\begin{array}{c}64 \\
77 \\
9 \\
13 \\
2\end{array}$ & 5 & 0.047 & N/A \\
\hline Education level $(n)$ & $\begin{array}{c}\text { Postgraduate } \\
\text { Graduate } \\
\text { Bachelor } \\
\text { Diploma } \\
\text { TAFE } \\
\text { Secondary edu } \\
\text { Primary edu }\end{array}$ & $\begin{array}{c}13 \\
3 \\
17 \\
4 \\
4 \\
4 \\
0\end{array}$ & $\begin{array}{c}8 \\
2 \\
14 \\
5 \\
1 \\
4 \\
0\end{array}$ & $\begin{array}{c}8 \\
1 \\
21 \\
3 \\
3 \\
4 \\
1\end{array}$ & $\begin{array}{c}11 \\
2 \\
20 \\
6 \\
2 \\
2 \\
1\end{array}$ & $\begin{array}{c}40 \\
8 \\
72 \\
19 \\
10 \\
14 \\
2\end{array}$ & 5 & 0.968 & N/A \\
\hline Ethnicity a $(n)$ & $\begin{array}{c}\text { Oceania } \\
\text { European } \\
\text { Arab } \\
\text { Asian } \\
\text { had }>1 \text { ethnicity }\end{array}$ & $\begin{array}{c}19 \\
14 \\
0 \\
7 \\
5\end{array}$ & $\begin{array}{c}18 \\
7 \\
0 \\
5 \\
3\end{array}$ & $\begin{array}{c}4 \\
2 \\
1 \\
35 \\
0\end{array}$ & $\begin{array}{c}4 \\
2 \\
0 \\
38 \\
0\end{array}$ & $\begin{array}{c}45 \\
25 \\
1 \\
85 \\
8\end{array}$ & 6 & $\leq 0.001 * 0125$ & N/A \\
\hline Ethnicity B $(n)$ & $\begin{array}{c}\text { Asian } \\
\text { Non-Asian }\end{array}$ & $\begin{array}{c}7 \\
39\end{array}$ & $\begin{array}{c}5 \\
28\end{array}$ & $\begin{array}{c}35 \\
7\end{array}$ & $\begin{array}{c}38 \\
6\end{array}$ & $\begin{array}{l}85 \\
80\end{array}$ & 5 & $\leq 0.001$ & N/A \\
\hline
\end{tabular}


TABLE 3: Continued.

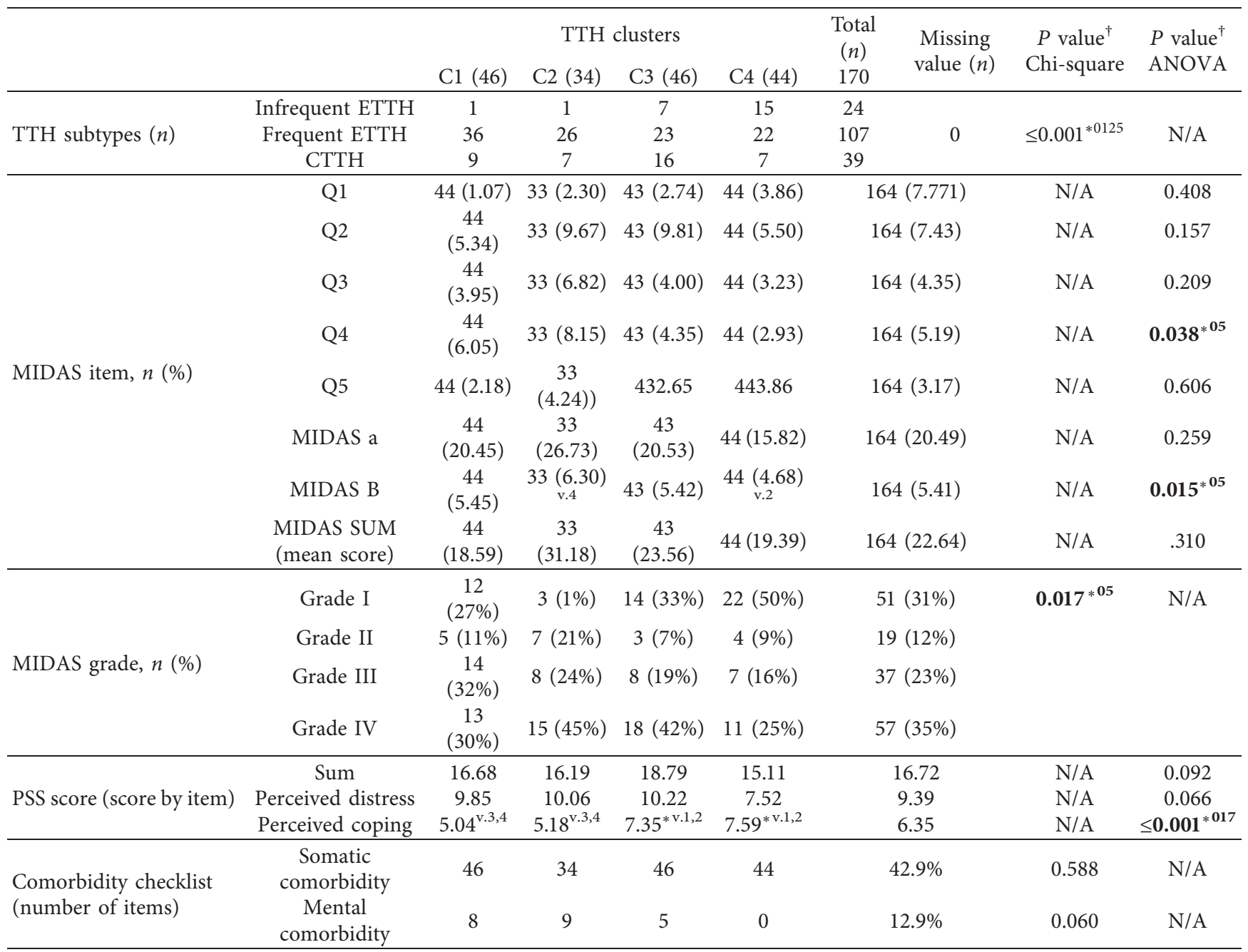

Note 1: Australia is a county of immigration. In the section of ethnicity, the category of "had more than 1 ethnicity" indicated a group of participants in this country shares more than one ethnicity. For example, an Australian person may have his/her mother of Irish ethnicity and father of Greek. In such case, these participants may tick two options, and in data analysis, he/she was classified as participant had more than one ethnicity. Note 2: both Chi-square and ANOVA were applied to access cluster differences for comparison. Chi-square tests examine categorical outcomes, whereas ANOVA assesses the means of each cluster. $P$ values correspond to comparisons between the clusters using Chi-square test or ANOVA, as appropriate. Note 3: in PSS-10, there are no cutoffs for "Perceived Distress" nor "Perceived Coping." A lower score in "Perceived Coping" factor reflects better coping ability since the four positively stated items (4, 5,7 , and 8 ) in this factor are reversed scored and then summing across all items when calculating the overall score. Note $4:{ }^{*} 05-$ the mean difference is significant at the 0.05 level; ${ }^{*} 0125$ - the mean difference is significant at the $0.0125(0.05 / 4)$ level; ${ }^{*} 017$-the mean difference is significant at the $0.017(0.05 / 3)$ level; " $v$ " denotes the clusters differed with post hoc Bonferroni correction, whereas the " $x$ (figure)" after " $v$ " indicates specific cluster or clusters.

scores. The level of disability, which ranged from grade I to grade IV (from low to high), was classified based on the MIDAS scores. The mean MIDAS SUM score of the current sample was 22.64 lost days, at a severe disability level (grade IV). There was a statistically significant cluster difference in the disability level $(P=0.17)$. This was largely due to about $50 \%$ the participants in clusters 2 and 3 having a higher level of disability (grades III and IV), whereas $50 \%$ of cluster 4 had the lowest level of disability (grade I). There were statistically significant cluster group differences in MIDAS items 4, which indicate the reduced productivity in household because of headaches, and MIDAS B, detecting the average pain on a $0-10$ scale. Post hoc $t$-tests with Bonferroni correction found clusters 2 and 4 were statistically different, with cluster 2 having more nonproductive days at home (8.2 days) due to headache and more severe headache (6.3) than cluster 4 (mean: 3 days, mean intensity: 4.7).

The average PSS score was 16.72. Compared with the normative data mean score of PSS-10 around $13[49,50]$, the existing sample had a relatively higher perceived stress than the general population. There was no cluster difference on PSS. PSS has two subscales: general distress (perceived distress; sum of items: 1, 2, 3, 6, 9, and 10) and coping ability (perceived coping; sum of items: 4, 5, 7, and 8) [56]. In this study, the average score for the "Perceived Distress" factor was 9.39, indicating a trend for a statistically significant cluster difference in this item $(P=0.066)$ with cluster 4 perceiving lower level of stress. A lower score of 6.35 was observed in "Perceived Coping" factor, 
reflecting better coping ability. The cluster difference in this item was statistically significant $(P<0.001)$ with participants in clusters 1 and 2 coping with stress better than the other two clusters.

Comorbidities of TTH participants were calculated by counting the total number of somatic comorbidities and mental comorbidities separately. All participants had a low number of comorbidities (Table 4 ). There were no significant differences in somatic comorbidities among the identified four TTH clusters. Although there was no statistically significant cluster difference in mental comorbidity, cluster 4 participants reported no mental comorbidity at all (Table 3).

3.3. Profile of the Clusters. Table 5 illustrates the profile of the four clusters. Cluster 1 had a moderate level of pain, moderate level of disability, and moderate distribution in both physical and mental comorbidity. Participants in this cluster tended to perform the best in coping ability (PSS "Perceived Coping" factor) when compared with other three clusters. Cluster 2 had the highest pain intensity and severest disability among all four patterns. This cluster also had the largest number of participants having a physical comorbidity. Cluster 3 had a very similar pattern to cluster 2 with moderate headache intensity and severe disability. However, based on CM understanding, they differed significantly in their presentation of headache and nonpainful symptoms. In addition to the symptomatology, they were also being significantly different from their coping with stress (cluster 3 is significant among clusters, whereas cluster 2 is not). Cluster 4 was unlabelled as there were insufficient characteristics of the symptoms and signs for CM diagnosis. It had the lowest level (mild) of pain intensity and lowest disability level among the four clusters.

\section{Discussion}

4.1. Summary of Findings. The present study identified three distinct CM patterns of TTH through a cluster analysis of 170 TTH participants in a bilingual cross-sectional survey. The results of this study suggest that TTH can be subdivided based on symptoms and signs that are significant to the CM diagnostic process. Those clusters may or may differ in the subtypes of TTH (ETTH, frequent ETTH, and CTTH), stress level, pain intensity, and disability level. These findings expand the existing understanding of TTH symptomatology in Western medicine and TTH patterns in CM, which may help advance our understanding of the symptoms associated with TTH and subgroups of TTH as well as contribute to enhanced clinical practice in CM.

4.2. Pros and Cons of Explorative Analytic Methods for CM Pattern Identification. The essence of factor analysis and cluster analysis is to classify a set of observations into groups. Such an approach could be a suitable technique in supporting and verifying the CM patterns as it has been used to explore and study CM patterns in order to understand a series of diseases and conditions defined by modern medicine [57-60]. Generally, those studies identified explainable CM patterns and interpreted those modern illness/diseases in a reasonable fashion.

Although the explorative analysis could be a valuable method for the study of CM pattern identification, the results of such analysis cannot be used directly in research or clinical practice without integration with CM theory. Hence, it is necessary to incorporate experts' opinions and clinical experience in order to ensure the results being clinically meaningful. In this study, we combined the two approaches for pattern identification.

Initially, through the TwoStep cluster analysis, we identified a four-cluster solution and a five-cluster solution. Experts agreed that the patterns within the four-cluster solution tended to coincide more with the actual clinical observation and were meaningful for pattern identification. By contrast, the five-cluster solution did not lead to distinct sound/logical CM patterns. Finally, the four-cluster solution was used, resulting in three identifiable patterns and one unidentifiable cluster. However, it is likely the unidentifiable cluster including a few factors that are not powerful enough to form their own patterns. From the statistical perspective of the PCA results, we observed that the overall mean score ("power") of the factors in cluster 4 was relatively "weak" (lower than 0.4) with most of the factor mean sores between 0.04 and 0.09 . Consequently, those factors were considered having little diagnostic value for CM pattern recognition. In addition, our relatively small sample size may have restricted the number of identifiable patterns.

In PCA, the coefficient, known as the "factor loading," refers to how strong each variable is associated with the proposed factor, is used to explain the correlation between the individual item and the overall factor [32]. As a rule of thumb, a factor loading below 0.4 indicates the loading condition is weak; 0.6 , a moderate level; between 0.6 and 0.8 , being large; and 0.8 or above, being very high [61]. We adopted 0.5 as the cutoff point. In contrast, in interpreting the results from TwoStep cluster analysis, the existing literature does not provide clear guiding rules for the cutoff mean score for including or excluding a factor within a cluster. In the present study, we used 0.4 of the cluster mean as the cutoff point. We then invited experts to interpret symptoms and signs and named each cluster to ensure clinical relevance. Three out of four clusters were labelled, reflecting this approach is workable (Appendix D).

4.3. Interpretation of Findings. The common TTH characteristics and associated symptoms identified in the present study are consistent with the findings of other studies [8-11]. The main similarities are the precipitating factors such as physical activity, stress/tension, when tired, lack of sleep, specific foods/drinks, alcohol, and skipping meals, and some accompanying symptoms such as fatigue, insomnia, and irritability. Emotion-related factors may have impacted on the presence of TTH. The present study found that stress and/or tension $(73.6 \%)$ was the leading precipitating factors, and the finding is consistent with others (49.4\% [8], 74.5\% [62], and $63 \%$ in men and $77 \%$ [63] and 52.5\% [11] in women). Only a small percentage of anxiety disorders and mood disorders 
TABLE 4: Summary of comorbidity checklist results.

\begin{tabular}{|c|c|c|c|}
\hline & Item & Frequency $(n)$ & $(\%)$ \\
\hline 1 & Cardiac & 6 & 3.5 \\
\hline 2 & Vascular & 11 & 6.5 \\
\hline 3 & Hematology & 2 & 1.2 \\
\hline 4 & Respiratory & 13 & 7.6 \\
\hline 5 & Ophthalmology and otorhinolaryngology & 15 & 8.8 \\
\hline 6 & Upper gastrointestinal & 16 & 9.4 \\
\hline 7 & Lower gastrointestinal & 4 & 2.4 \\
\hline 8 & Hepatic and pancreatic & 3 & 1.8 \\
\hline 9 & Renal & 3 & 1.8 \\
\hline 10 & Genitourinary & 3 & 1.8 \\
\hline 11 & Musculoskeletal-integumentary & 13 & 7.6 \\
\hline 12 & Neurological & 4 & 2.4 \\
\hline 13 & Endocrine-metabolic & 6 & 3.5 \\
\hline 14 & Psychiatric & 13 & 7.6 \\
\hline 15 & Female hormonal and reproductive & 10 & 5.9 \\
\hline+1 & Anxiety disorders & 12 & 7.1 \\
\hline+2 & Mood disorders & 12 & 7.1 \\
\hline+3 & Substance use disorders & 2 & 1.2 \\
\hline
\end{tabular}

were detected $(7.1 \%$, respectively). This is probably due to more than three quarters of the respondents were ETTH sufferers, as it has been shown that psychiatric comorbidities are more common in CTTH patients $[64,65]$, whereas those having less frequent TTH tend to have less psychiatric comorbidity [66]. Such method has been used in other exploratory research $[67,68]$.

Very few studies have examined the differences between ETTH and CTTH beyond headache days. In the present study, the four CM patterns differed in the TTH subtypes. The three CM patterns not only differ in headache frequency but also in headache intensity and disability. Over three quarters of participants in clusters 1 and 2 had frequent ETTH, and about one-fifth had CTTH, whereas one-third in cluster 3 had CTTH, and half had frequent ETTH. All these three clusters had very few participants with infrequent ETTH, whereas one-third of cluster 4 was having infrequent ETTH ( $<1$ day). Those results indicate that subtypes of TTH go beyond frequency of TTH. They could differ in clinical presentation of headache as well as accompanied signs and symptoms.

We also found that, over three quarters of participants in clusters 3 and 4 were of Asian origin, but over three quarters of those in clusters 1 and 2 were of non-Asian (Oceania and European) origin. In our further analysis (Appendix E), over $40 \%$ of Asian participants were at MIDAS level 1, comparing with $20 \%$ in the non-Asian group, reflecting mild impact of TTH on function. Consistently, over one-fifth of Asian participants (22\%) suffered from infrequent headache, compared with $5 \%$ of non-Asian participants did. The former also tended to have poor coping ability as assessed with PSS. Those findings are consistent with differences in four clusters identified in the current study. The ethnic difference in cluster is, therefore, likely due to the frequency and severity of headache and coping strategies, rather than differences in ethnicity. This question is, however, beyond the scope of this paper, which aims to assess if advanced statistical methods could help with TTH CM syndrome differentiation. Future studies with larger sample sizes could examine the impact of demographic features on TTH patterns.

\subsection{Implications of the Pattern Exploration for Clinical} Treatment. Currently, there is a significant gap in understanding subtypes of TTH. The IHS diagnostic criteria for TTH are designed to distinguish TTH from other types of headaches to some degree and to classify TTH into three subtypes based upon attack frequency only. Nonheadache symptoms associated with TTH are, however, not explained or accounted for. Furthermore, despite several epidemiological studies observing a series of aggravating and relieving factors and accompanying symptoms of TTH, clinical practice to date has not given adequate attention to TTH symptoms. The current study fills those gaps by using knowledge of pattern identification in CM and advanced statistical methods and identified three clinically meaningful subgroups of TTH. In addition, the identified four clusters not only differed in symptoms and signs but also in the level of disability and stress. Among them, cluster 2 had the most severe headache and highest disability level, whereas cluster 4 had mildest headache intensity, moderate disability, and was free from mental comorbidity. The presence of these subgroups of TTH indicates that there is a need to go beyond frequency of TTH, as it is possible to subcategorize TTH from a multidimensional perspective, but not just limited to the frequency of headache. Addressing headache as well as accompanying nonheadache symptoms may lead to more efficient, individualised treatment strategies. The PSS score in ascendant hyperactivity of liver yang and liver depression forming fire is high, indicating emotional stress. This needs to be acknowledged by CM practitioners. Whether CM treatment modalities are adequate for addressing those emotional difficulties is yet to be examined. In the West, psychological interventions are often used to specifically address those 
TABLE 5: Relationship between patterns and other outcome measures.

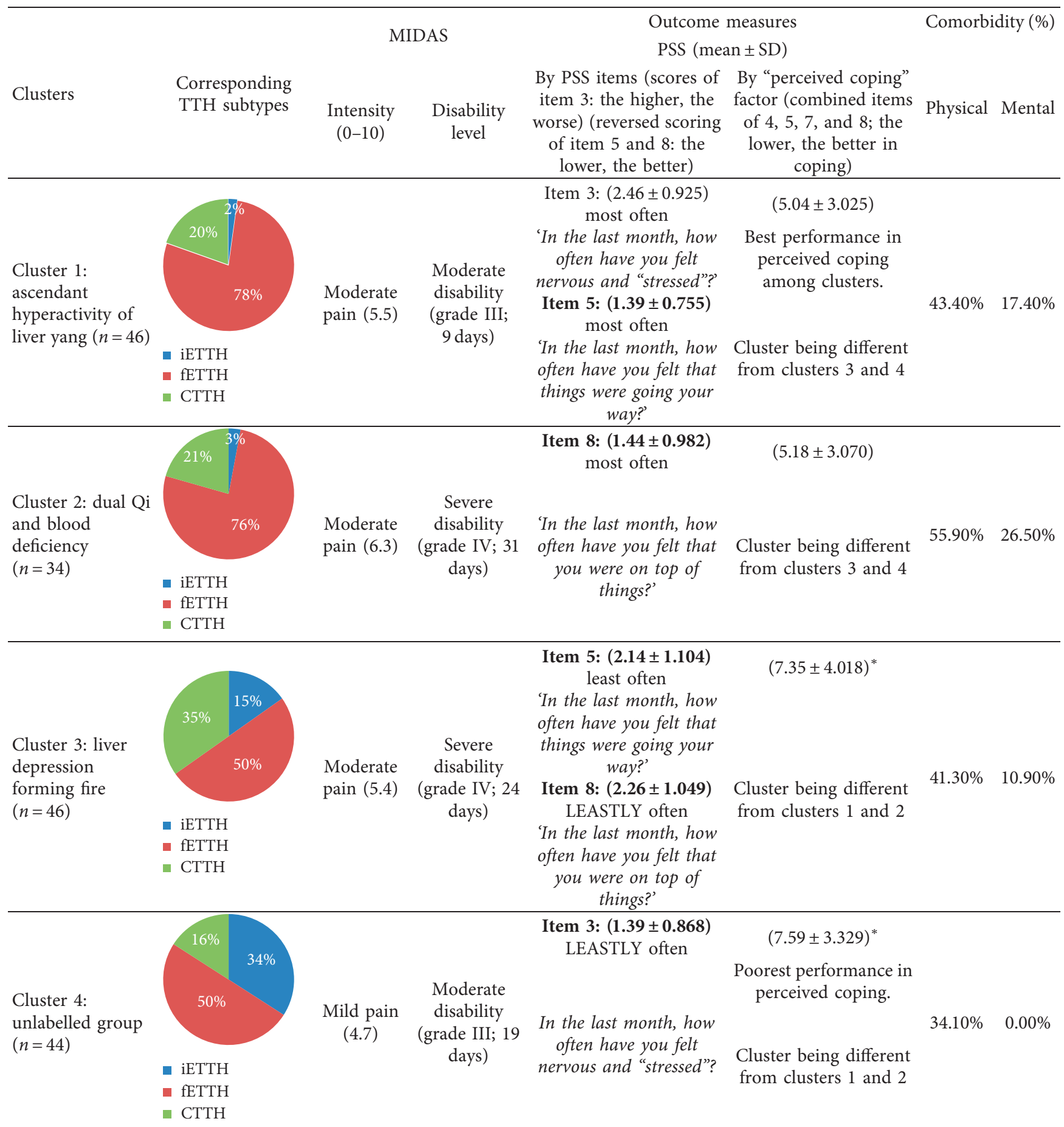

Note 1: in this table, "iETTH" stands for "infrequent ETTH," whereas the "fETTH" is the abbreviation of "frequent ETTH." Note 2: “*”: the mean difference of PSS is significant among clusters at the $0.17(0.05 / 3)$ level.

problems. Patients presented with either of the two patterns may require additional psychological interventions to bring out the best therapeutic effects.

4.5. Strengths. To our best knowledge, the present investigation is the first study using exploratory statistical method to research TTH-related symptoms as well as identifying CM patterns of TTH. Our study is the first step towards a better understanding of TTH from both CM and modern medicine aspects. This study has a few important strengths. Firstly, our method provides an alternative to current modern medicine approaches in understanding features of TTH and its subgroups, contributing essential information for future research. These results expanded the common understanding of TTH symptomatology in terms of its pain description, 
TABLE 6: In which areas does your headache mostly occur and how often? (Please tick $(\checkmark)$ one box for each item).

\begin{tabular}{|c|c|c|c|c|c|}
\hline Location of headache & Never & Seldom & Sometimes & Often & Almost always \\
\hline Forehead (front of the head) & $\square$ & $\square$ & $\square$ & $\square$ & $\square$ \\
\hline Side of the head (left side) & $\square$ & $\square$ & $\square$ & $\square$ & $\square$ \\
\hline Side of the head (right side) & $\square$ & $\square$ & $\square$ & $\square$ & $\square$ \\
\hline Back of the head & $\square$ & $\square$ & $\square$ & $\square$ & $\square$ \\
\hline Top of the head & $\square$ & $\square$ & $\square$ & $\square$ & $\square$ \\
\hline Whole head & $\square$ & $\square$ & $\square$ & $\square$ & $\square$ \\
\hline $\begin{array}{l}\text { No particular location } \\
\text { Others (please specify) }\end{array}$ & $\square$ & $\square$ & $\square$ & $\square$ & $\square$ \\
\hline
\end{tabular}

TABLE 7: When you have a headache, do you ever have discomfort (pain, tension, or tenderness) in the following areas? (Please tick ( $\checkmark$ ) one box for each item).

\begin{tabular}{lccccc}
\hline Affected area & Never & Seldom & Sometimes & Often & Almost always \\
\hline Neck & $\square$ & $\square$ & $\square$ & $\square$ & $\square$ \\
Shoulders & $\square$ & $\square$ & $\square$ & $\square$ & $\square$ \\
Ears & $\square$ & $\square$ & $\square$ & $\square$ & $\square$ \\
Eyebrow & $\square$ & $\square$ & $\square$ & $\square$ & $\square$ \\
Eyes & $\square$ & $\square$ & $\square$ & $\square$ & $\square$ \\
Face & $\square$ & $\square$ & $\square$ & $\square$ & $\square$ \\
Cheeks & $\square$ & $\square$ & $\square$ & $\square$ \\
Jaw & $\square$ & $\square$ & & $\square$ \\
Nose/bridge of nose & $\square$ & $\square$ & $\square$ & $\square$ \\
Others (please specify) & & $\square$ & $\square$ & $\square$ \\
\hline
\end{tabular}

TABLE 8: What is the sensation of your headache? (Please tick $(\checkmark)$ as many items as applicable).

\begin{tabular}{|c|c|c|c|c|}
\hline$\square$ Pressing & $\square$ Explosive & $\square$ Burning & $\square$ Drilling & $\square$ Cutting \\
\hline$\square$ Sharp & $\square$ Vague & $\square$ Heavy & $\square$ Dull & $\square$ Throbbing \\
\hline$\square$ Pulling & $\square$ Empty & $\square$ Tight & $\square$ Distending & $\square$ Piercing \\
\hline $\begin{array}{l}\square \text { Pulsating } \\
\text { Others (plea }\end{array}$ & $\square$ Radiating & $\square$ Pounding & $\square$ A "band-like" sensation around the head & \\
\hline
\end{tabular}

TABLE 9: When you have a headache, what is the nature of the headache? (Please tick $(\checkmark)$ one box for each item).

Fixed (headache with fixed location)

Moves (headache moves around the head or shifting from side to side)

Continuous (constant, persistent, nonstop headache)

Intermittent (headache comes and goes, occasional, or periodically occurring)
Never Seldom Sometimes Often Almost always

$\begin{array}{lllll}\square & \square & \square & \square & \square \\ \square & \square & \square & \square & \square \\ \square & \square & \square & \square & \square \\ \square & \square & \square & \square & \square\end{array}$

TABLe 10: Over the last 3 months, on average, how many days per month did you have a headache? (Please tick $(\checkmark)$ one of the three options).

$\begin{array}{lll}\square \text { Less than one day } \square \text { Between } 1 \text { and } 14 \text { days } & \square \text { days or more }\end{array}$

trigger factors, and accompanying symptoms. Secondly, our results fill the significant gap in the existing literature of $\mathrm{CM}$ on headaches, which there is lack of differentiation of TTH from other types of headaches, such as migraine or secondary headache. Through recruiting only TTH sufferers and using a validated questionnaire, we were able to collect comprehensive data of TTH that are of clinical significance to CM. Thirdly, the existing CM patterns of TTH in the literature relied on expert opinions alone. Our study used the evidence-based approach of combining exploratory data analysis with expert opinions to ensure the objectivity and clinical significance of our findings.
4.6. Limitations. There are several limitations of the current study. Firstly, the present results could be limited due to its sample size, as some other possible patterns may be observed with a larger sample size. Secondly, relying on exploratory analysis or expert opinion alone has its drawbacks. Statistically determined clusters can be affected by many factors. Expert opinions may be subjective. The present study combines both approaches to minimize this limit. Lastly, this study is a cross-sectional study, which only analyses the symptom distribution collected at a specific duration over the last 3 months. The presence and the severity of symptoms observed may change over time. Future studies may use 
TABLE 11: During the course of the day, when does your headache get worse? (Please tick $(\checkmark)$ as many items as applicable).

\begin{tabular}{lcc}
\hline$\square$ Worse in the morning & $\square$ Worse in the afternoon & $\square$ Worse at the end of the day \\
$\square$ Worse at night & $\square$ All day & $\square$ No particular time
\end{tabular}

TABle 12: What aggravates your headache? (Please tick $(\checkmark)$ one box for each item).

\begin{tabular}{|c|c|c|c|c|c|c|}
\hline Increased tension & $\begin{array}{l}\text { Don't } \\
\text { know }\end{array}$ & Never & Seldom & Sometimes & Often & $\begin{array}{c}\text { Almost } \\
\text { always }\end{array}$ \\
\hline Overwork (e.g., prolonged working hours, long periods of studying/typing) & $\square$ & $\square$ & $\square$ & $\square$ & $\square$ & $\square$ \\
\hline When tired & $\square$ & $\square$ & $\square$ & $\square$ & $\square$ & $\square$ \\
\hline Mental strain (e.g., overthinking or other concentration) & $\square$ & $\square$ & $\square$ & $\square$ & $\square$ & $\square$ \\
\hline Eyestrain (e.g., reading, computer, or TV) & $\square$ & $\square$ & $\square$ & $\square$ & $\square$ & $\square$ \\
\hline Muscular strain (muscle tightness) & $\square$ & $\square$ & $\square$ & $\square$ & $\square$ & $\square$ \\
\hline Physical labour & $\square$ & $\square$ & $\square$ & $\square$ & $\square$ & $\square$ \\
\hline Lack of sleep & $\square$ & $\square$ & $\square$ & $\square$ & $\square$ & $\square$ \\
\hline Poor posture in sitting, standing or sleeping & $\square$ & $\square$ & $\square$ & $\square$ & $\square$ & $\square$ \\
\hline \multicolumn{7}{|l|}{ Diet } \\
\hline Alcohol & $\square$ & $\square$ & $\square$ & $\square$ & $\square$ & $\square$ \\
\hline Coffee & $\square$ & $\square$ & $\square$ & $\square$ & $\square$ & $\square$ \\
\hline Dehydration & $\square$ & $\square$ & $\square$ & $\square$ & $\square$ & $\square$ \\
\hline Hunger/being hungry & $\square$ & $\square$ & $\square$ & $\square$ & $\square$ & $\square$ \\
\hline Chocolate & $\square$ & $\square$ & $\square$ & $\square$ & $\square$ & $\square$ \\
\hline Cigarette smoking & $\square$ & $\square$ & $\square$ & $\square$ & $\square$ & $\square$ \\
\hline Soft drink/sodas & $\square$ & $\square$ & $\square$ & $\square$ & $\square$ & $\square$ \\
\hline Tea & $\square$ & $\square$ & $\square$ & $\square$ & $\square$ & $\square$ \\
\hline Cheese & $\square$ & $\square$ & $\square$ & $\square$ & $\square$ & $\square$ \\
\hline Dairy foods (e.g., milk, ice cream, etc.) & $\square$ & $\square$ & $\square$ & $\square$ & $\square$ & $\square$ \\
\hline Monosodium glutamate (MSG) & $\square$ & $\square$ & $\square$ & $\square$ & $\square$ & $\square$ \\
\hline Sugar/too much sugar & $\square$ & $\square$ & $\square$ & $\square$ & $\square$ & $\square$ \\
\hline Spicy food & $\square$ & $\square$ & $\square$ & $\square$ & $\square$ & $\square$ \\
\hline Overconsumption of oily food & $\square$ & $\square$ & $\square$ & $\square$ & $\square$ & $\square$ \\
\hline Irregular diet (e.g., eating on the run, skip meals) & $\square$ & $\square$ & $\square$ & $\square$ & $\square$ & $\square$ \\
\hline \multicolumn{7}{|l|}{ Weather } \\
\hline Change of weather & $\square$ & $\square$ & $\square$ & $\square$ & $\square$ & $\square$ \\
\hline Change in temperature & $\square$ & $\square$ & $\square$ & $\square$ & $\square$ & $\square$ \\
\hline Exposure to bright lights or sunshine & $\square$ & $\square$ & $\square$ & $\square$ & $\square$ & $\square$ \\
\hline Hot weather & $\square$ & $\square$ & $\square$ & $\square$ & $\square$ & $\square$ \\
\hline Cold weather & $\square$ & $\square$ & $\square$ & $\square$ & $\square$ & $\square$ \\
\hline Windy days & $\square$ & $\square$ & $\square$ & $\square$ & $\square$ & $\square$ \\
\hline Damp weather/humid weather & $\square$ & $\square$ & $\square$ & $\square$ & $\square$ & $\square$ \\
\hline Rainy days & $\square$ & $\square$ & $\square$ & $\square$ & $\square$ & $\square$ \\
\hline \multicolumn{7}{|l|}{ Stress and emotional changes } \\
\hline Stress & $\square$ & $\square$ & $\square$ & $\square$ & $\square$ & $\square$ \\
\hline Nervousness & $\square$ & $\square$ & $\square$ & $\square$ & $\square$ & $\square$ \\
\hline Anger or irritability & $\square$ & $\square$ & $\square$ & $\square$ & $\square$ & $\square$ \\
\hline Anxiety (excessive worry) & $\square$ & $\square$ & $\square$ & $\square$ & $\square$ & $\square$ \\
\hline Depression (feeling unhappy or depressed) & $\square$ & $\square$ & $\square$ & $\square$ & $\square$ & $\square$ \\
\hline $\begin{array}{l}\text { Tension or conflict-related (e.g., from financial constraints, family, } \\
\text { relationship, and/or work) }\end{array}$ & $\square$ & $\square$ & $\square$ & $\square$ & $\square$ & $\square$ \\
\hline \multicolumn{7}{|l|}{ Other factors } \\
\hline Sneezing & $\square$ & $\square$ & $\square$ & $\square$ & $\square$ & $\square$ \\
\hline Teeth grinding & $\square$ & $\square$ & $\square$ & $\square$ & $\square$ & $\square$ \\
\hline Other (please specify) & & & & & & \\
\hline
\end{tabular}


TABLe 13: What relieves your headache? (Please tick $(\checkmark)$ one box for each item).

\begin{tabular}{|c|c|c|c|c|c|c|}
\hline & Don't know & Never & Seldom & Sometimes & Often & Almost always \\
\hline Rest & $\square$ & $\square$ & $\square$ & $\square$ & $\square$ & $\square$ \\
\hline Lying down & $\square$ & $\square$ & $\square$ & $\square$ & $\square$ & $\square$ \\
\hline Sleeping & $\square$ & $\square$ & $\square$ & $\square$ & $\square$ & $\square$ \\
\hline Medication & $\square$ & $\square$ & $\square$ & $\square$ & $\square$ & $\square$ \\
\hline Exercise/light exercise & $\square$ & $\square$ & $\square$ & $\square$ & $\square$ & $\square$ \\
\hline Massage & $\square$ & $\square$ & $\square$ & $\square$ & $\square$ & $\square$ \\
\hline Pressing/applying pressure on the pain area & $\square$ & $\square$ & $\square$ & $\square$ & $\square$ & $\square$ \\
\hline Eating & $\square$ & $\square$ & $\square$ & $\square$ & $\square$ & $\square$ \\
\hline Warmth (e.g., warm environment, hot drink, hot pack, hot shower, etc.) & $\square$ & $\square$ & $\square$ & $\square$ & $\square$ & $\square$ \\
\hline $\begin{array}{l}\text { Coldness (e.g., cold environment, cold drink, cold pack, cold shower, } \\
\text { etc.) } \\
\text { Others (please specify) }\end{array}$ & $\square$ & $\square$ & $\square$ & $\square$ & $\square$ & $\square$ \\
\hline
\end{tabular}

TABLE 14: Do you have any of the following symptoms that may or may not be related to your headache? (Please tick $(\checkmark)$ one box for each item).

\begin{tabular}{|c|c|c|c|c|c|}
\hline Eye-related & Never & Seldom & Sometimes & Often & Almost always \\
\hline Sensitivity to light (or to bright lights) & $\square$ & $\square$ & $\square$ & $\square$ & $\square$ \\
\hline Dry eyes & $\square$ & $\square$ & $\square$ & $\square$ & $\square$ \\
\hline Teary eyes & $\square$ & $\square$ & $\square$ & $\square$ & $\square$ \\
\hline Blurred vision & $\square$ & $\square$ & $\square$ & $\square$ & $\square$ \\
\hline Sore eyes & $\square$ & $\square$ & $\square$ & $\square$ & $\square$ \\
\hline Red eyes & $\square$ & $\square$ & $\square$ & $\square$ & $\square$ \\
\hline Swollen eyelids & $\square$ & $\square$ & $\square$ & $\square$ & $\square$ \\
\hline Eye twitching & $\square$ & $\square$ & $\square$ & $\square$ & $\square$ \\
\hline Floaters in the eyes & $\square$ & $\square$ & $\square$ & $\square$ & $\square$ \\
\hline Burning sensation in the eyes & $\square$ & $\square$ & $\square$ & $\square$ & $\square$ \\
\hline Itchy sensation in the eyes & $\square$ & $\square$ & $\square$ & $\square$ & $\square$ \\
\hline \multicolumn{6}{|l|}{ Face related (mouth, ear, and nose) } \\
\hline Sensitivity to sound (or to loud noises) & $\square$ & $\square$ & $\square$ & $\square$ & $\square$ \\
\hline Dry mouth & $\square$ & $\square$ & $\square$ & $\square$ & $\square$ \\
\hline Thirst & $\square$ & $\square$ & $\square$ & $\square$ & $\square$ \\
\hline Bitter taste in the mouth & $\square$ & $\square$ & $\square$ & $\square$ & $\square$ \\
\hline Runny nose & $\square$ & $\square$ & $\square$ & $\square$ & $\square$ \\
\hline Sore throat/feeling of foreign body in the throat & $\square$ & $\square$ & $\square$ & $\square$ & $\square$ \\
\hline Ear discharge & $\square$ & $\square$ & $\square$ & $\square$ & $\square$ \\
\hline Tinnitus (ringing in the ears) & $\square$ & $\square$ & $\square$ & $\square$ & $\square$ \\
\hline Flushed face/hot red face & $\square$ & $\square$ & $\square$ & $\square$ & $\square$ \\
\hline \multicolumn{6}{|l|}{ Digestion-related } \\
\hline Nausea & $\square$ & $\square$ & $\square$ & $\square$ & $\square$ \\
\hline Vomiting & $\square$ & $\square$ & $\square$ & $\square$ & $\square$ \\
\hline Reflux & $\square$ & $\square$ & $\square$ & $\square$ & $\square$ \\
\hline Belching & $\square$ & $\square$ & $\square$ & $\square$ & $\square$ \\
\hline Bloating/flatulence & $\square$ & $\square$ & $\square$ & $\square$ & $\square$ \\
\hline Indigestion & $\square$ & $\square$ & $\square$ & $\square$ & $\square$ \\
\hline Poor appetite/loss of appetite & $\square$ & $\square$ & $\square$ & $\square$ & $\square$ \\
\hline \multicolumn{6}{|l|}{ Urine and bowel related } \\
\hline Yellowish urine & $\square$ & $\square$ & $\square$ & $\square$ & $\square$ \\
\hline Frequent urination (especially at night) & $\square$ & $\square$ & $\square$ & $\square$ & $\square$ \\
\hline Watery bowel motion & $\square$ & $\square$ & $\square$ & $\square$ & $\square$ \\
\hline Loose bowel motion & $\square$ & $\square$ & $\square$ & $\square$ & $\square$ \\
\hline Dry stools & $\square$ & $\square$ & $\square$ & $\square$ & $\square$ \\
\hline Constipation & $\square$ & $\square$ & $\square$ & $\square$ & $\square$ \\
\hline \multicolumn{6}{|l|}{ Muscle- and joint-related } \\
\hline Joint stiffness & $\square$ & $\square$ & $\square$ & $\square$ & $\square$ \\
\hline Neck stiffness & $\square$ & $\square$ & $\square$ & $\square$ & $\square$ \\
\hline Muscle twitching & $\square$ & $\square$ & $\square$ & $\square$ & $\square$ \\
\hline Weak legs and knees & $\square$ & $\square$ & $\square$ & $\square$ & $\square$ \\
\hline
\end{tabular}


TABLE 14: Continued.

Feeling weak in the lower back

Feeling cold in the lower back or lower back pain worsened by coldness

Cold hands and feet/cold limbs

Hot sensation in the palms

"Pins and needles" or numbness in the hands and/or feet

\begin{tabular}{lllll}
$\square$ & $\square$ & $\square$ & $\square$ & $\square$ \\
$\square$ & $\square$ & $\square$ & $\square$ & $\square$ \\
$\square$ & $\square$ & $\square$ & $\square$ & $\square$ \\
$\square$ & $\square$ & $\square$ & $\square$ & $\square$ \\
$\square$ & $\square$ & $\square$ & $\square$ & $\square$ \\
\hline
\end{tabular}

Other symptoms

Increased forgetfulness or poor memory

Feeling depressed

Irritability/irascibility (short-tempered, easily angered)

Restlessness

Fatigue/tiredness

Faintness

Heavy sensation in the body

Insomnia (difficulty falling asleep or staying asleep)

Sighing often

Feverish sensation

Shortness of breath

Dizziness

Excessive phlegm

Palpitation (feeling the heart beats quickly or unusually)

Inability to concentrate

Night sweating

Sweating upon mild activity

Aversion to cold or fear of being cold

Aversion to hot or fear of being hot

Sensitive to temperature changes

Others (please specify)

TABLE 15: Apart from headache, do you experience pain in any other parts of your body? (Please tick $(\checkmark)$ as many items as applicable).

\begin{tabular}{llll}
\hline$\square$ Neck & $\square$ Shoulder & $\square$ Jaw & $\square$ Throat \\
$\square$ Ears & $\square$ Eyes & $\square$ Chest & $\square$ Breasts \\
$\square$ Upper back & $\square$ Middle back & $\square$ Lower back & $\square$ Abdomen \\
$\square$ Arms & $\square$ Legs & $\square$ Knees & $\square$ Heel \\
$\square$ Hips & $\square$ Buttocks & $\square$ Flank (side of the body) & $\square$ Hypochondria (lower abdomen) \\
Others (please specify) & & \\
\hline
\end{tabular}

TABLE 16: Information related to women's health (Only female participants need to fill in this section. This section is about women's health which may relate to your headache.).

\begin{tabular}{lc}
\hline & 3.3.1. Do you still have periods? \\
\hline & If no, please ignore section (3.3.2) and tick the following reasons \\
& $\square$ Menopause \\
& $\square$ Hysterectomy \\
$\square$ No & $\square$ Contraceptive pill \\
& $\square$ Other medications \\
& $\square$ Other underlying diseases \\
$\square$ Pes & $\square$ Others (please specify) \\
$\square$ Yese & If Yes, please complete the next section (3.3.2)
\end{tabular}

TABLE 17: Information related to women's health (continued) (please tick $(\checkmark)$ one box for each item).

\begin{tabular}{|c|c|c|c|c|c|}
\hline & Never & Seldom & Sometimes & Often & Almost always \\
\hline Irregular period cycle & $\square$ & $\square$ & $\square$ & $\square$ & $\square$ \\
\hline Early periods (shortened menstrual cycle) & $\square$ & $\square$ & $\square$ & $\square$ & $\square$ \\
\hline Delayed periods (prolonged menstrual cycle) & $\square$ & $\square$ & $\square$ & $\square$ & $\square$ \\
\hline Light bleeding (bleeding less than normal) & $\square$ & $\square$ & $\square$ & $\square$ & $\square$ \\
\hline Excessive bleeding & $\square$ & $\square$ & $\square$ & $\square$ & $\square$ \\
\hline
\end{tabular}


TABle 17: Continued.

\begin{tabular}{|c|c|c|c|c|c|}
\hline & Never & Seldom & Sometimes & Often & Almost always \\
\hline Bleeding with clots & $\square$ & $\square$ & $\square$ & $\square$ & $\square$ \\
\hline Bright red-coloured menstrual blood & $\square$ & $\square$ & $\square$ & $\square$ & $\square$ \\
\hline Light red-coloured menstrual blood & $\square$ & $\square$ & $\square$ & $\square$ & $\square$ \\
\hline Dark-coloured menstrual blood & $\square$ & $\square$ & $\square$ & $\square$ & $\square$ \\
\hline Excessive watery discharge & $\square$ & $\square$ & $\square$ & $\square$ & $\square$ \\
\hline Yellow discharge & $\square$ & $\square$ & $\square$ & $\square$ & $\square$ \\
\hline Headache during period & $\square$ & $\square$ & $\square$ & $\square$ & $\square$ \\
\hline Headache after period & $\square$ & $\square$ & $\square$ & $\square$ & $\square$ \\
\hline Abdominal pain before periods & $\square$ & $\square$ & $\square$ & $\square$ & $\square$ \\
\hline Abdominal pain during periods & $\square$ & $\square$ & $\square$ & $\square$ & $\square$ \\
\hline Abdominal pain after periods & $\square$ & $\square$ & $\square$ & $\square$ & $\square$ \\
\hline Lower back pain before periods & $\square$ & $\square$ & $\square$ & $\square$ & $\square$ \\
\hline Lower back pain during periods & $\square$ & $\square$ & $\square$ & $\square$ & $\square$ \\
\hline Lower back pain after periods & $\square$ & $\square$ & $\square$ & $\square$ & $\square$ \\
\hline Others (please specify) & & & & & \\
\hline
\end{tabular}

TABLE 18: Do you have any other diseases or health conditions diagnosed by your medical doctor? $\square$ No. $\square$ Yes. If yes, please tick the following listed conditions that apply to you (Please tick $(\checkmark)$ as many items as applicable).

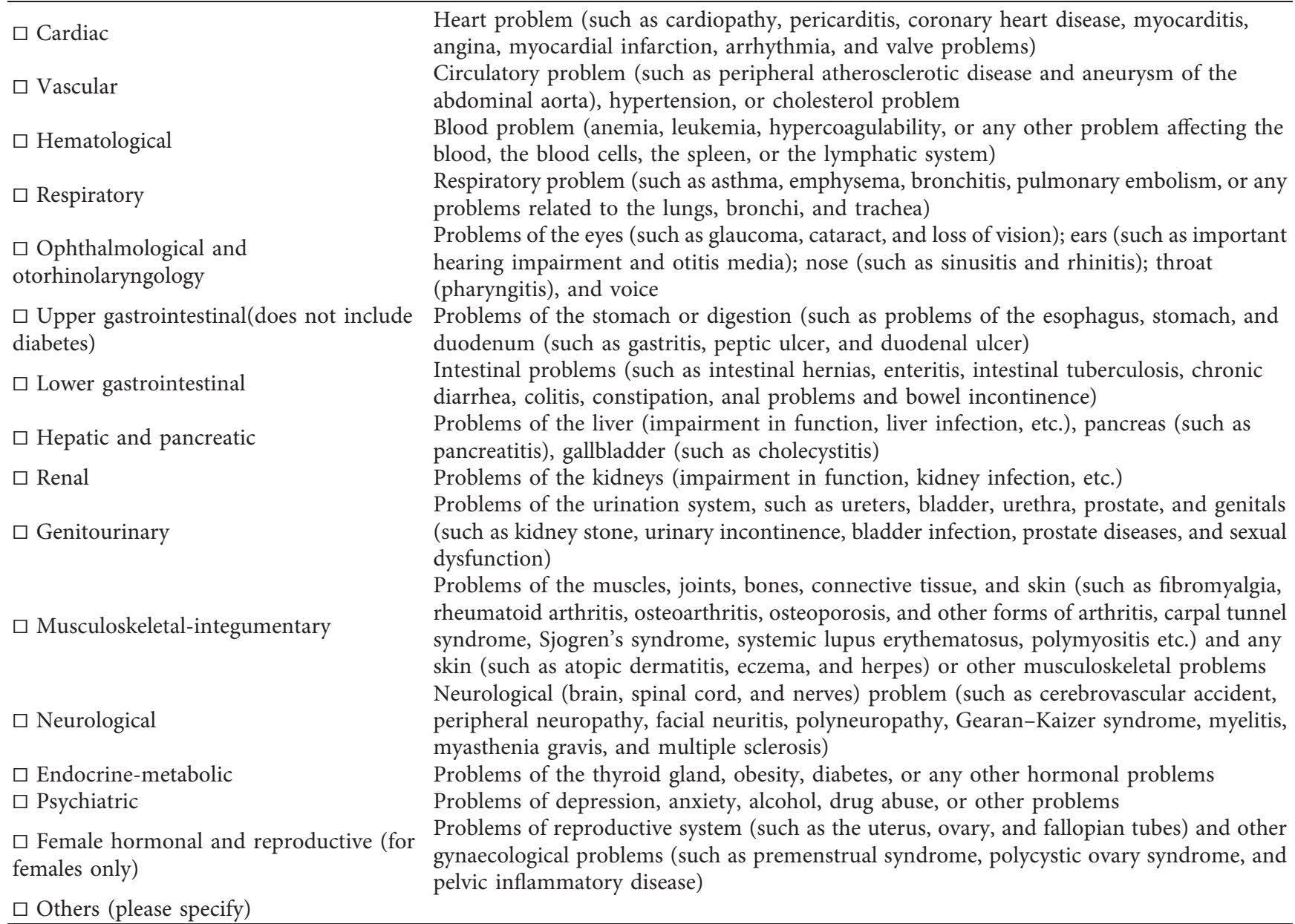


TABLE 19: Have you been diagnosed by a medical doctor with any of the following mental health conditions? $\square$ No. $\square$ Yes. If yes, please tick the following listed conditions that apply to you.

$\square$ Anxiety disorders Includes anxiety, panic disorder, obsessive-compulsive disorder, posttraumatic stress disorder, agoraphobia, and

$\square$ Mood disorders social phobia

$\square$ Substance use

disorders

Includes depression, mania, and bipolar (affective) disorder

$\square$ Others (please

Includes dependence or harmful use of alcohol, or drugs (opioids, sedatives, stimulants, cannabinoids, petrol, specify)

TABLE 20: Rotated component matrix for CMHQ factor extraction.

\begin{tabular}{|c|c|c|c|c|c|c|c|c|c|c|c|c|c|c|c|c|c|}
\hline \multirow{2}{*}{ CMHQ item } & \multicolumn{17}{|c|}{ Part I component } \\
\hline & 1 & 2 & 3 & 4 & 5 & 6 & 7 & 8 & 9 & 10 & 11 & 12 & 13 & 14 & 15 & 16 & 17 \\
\hline $\begin{array}{ll}1.1 \\
\end{array}$ & 0.755 & & & & & & & & & & & & & & & & \\
\hline 1.1 .2 & & & 0.830 & & & & & & & & & & & & & & \\
\hline 1.1.3 & & & 0.814 & & & & & & & & & & & & & & \\
\hline 1.1 .4 & 0.731 & & & & & & & & & & & & & & & & \\
\hline 1.1.5 & 0.673 & & & & & & & & & & & & & & & & \\
\hline 1.1.6 & & 0.718 & & & & & & & & & & & & & & & \\
\hline 1.1.7 & & 0.915 & & & & & & & & & & & & & & & \\
\hline 1.2 .1 & 0.937 & & & & & & & & & & & & & & & & \\
\hline 1.2 .2 & 0.928 & & & & & & & & & & & & & & & & \\
\hline \multicolumn{18}{|l|}{1.2 .3} \\
\hline 1.2 .4 & & 0.723 & & & & & & & & & & & & & & & \\
\hline 1.2 .5 & & 0.610 & & & & & & & & & & & & & & & \\
\hline \multicolumn{18}{|l|}{1.2 .6} \\
\hline 1.2 .7 & & 0.759 & & & & & & & & & & & & & & & \\
\hline \multicolumn{18}{|l|}{1.2 .8} \\
\hline \multicolumn{18}{|l|}{1.2 .9} \\
\hline 1.3 .1 & & & & & 0.555 & & & & & & & & & & & & \\
\hline 1.3 .2 & & 0.734 & & & & & & & & & & & & & & & \\
\hline 1.3 .3 & & & & & 0.746 & & & & & & & & & & & & \\
\hline \multicolumn{18}{|l|}{$\begin{array}{l}1.3 .5 \\
1.3 .4\end{array}$} \\
\hline 1.3.5 & & & & & & 0.804 & & & & & & & & & & & \\
\hline 1.3.6 & & & 0.577 & & & & & & & & & & & & & & \\
\hline \multicolumn{18}{|l|}{1.3 .7} \\
\hline 1.3 .8 & & & & & & & -0.570 & & & & & & & & & & \\
\hline 1.3 .9 & & -0.584 & & & & & & & & & & & & & & & \\
\hline 1.3 .10 & & & & & & 0.627 & & & & & & & & & & & \\
\hline 1.3 .11 & & & & & & & 0.768 & & & & & & & & & & \\
\hline 1.3 .12 & & & & & & & & .882 & & & & & & & & & \\
\hline 1.3 .13 & 0.789 & & & & & & & & & & & & & & & & \\
\hline 1.3 .14 & & & 0.800 & & & & & & & & & & & & & & \\
\hline 1.3 .15 & & & & 0.636 & & & & & & & & & & & & & \\
\hline 1.3 .16 & 0.674 & & & & & & & & & & & & & & & & \\
\hline 1.3.17 & & & & & 0.640 & & & & & & & & & & & & \\
\hline 1.3 .18 & 0.744 & & & & & & & & & & & & & & & & \\
\hline 1.3 .19 & & & & 0.803 & & & & & & & & & & & & & \\
\hline 1.6 .1 & & 0.811 & & & & & & & & & & & & & & & \\
\hline 1.6 .2 & 0.774 & & & & & & & & & & & & & & & & \\
\hline 1.6 .3 & 0.706 & & & & & & & & & & & & & & & & \\
\hline 1.6 .4 & & 0.672 & & & & & & & & & & & & & & & \\
\hline 1.6 .5 & & & 0.984 & & & & & & & & & & & & & & \\
\hline 1.6 .6 & -0.765 & & & & & & & & & & & & & & & & \\
\hline \multirow{2}{*}{ CMHQ item } & \multicolumn{17}{|c|}{ Part II component } \\
\hline & 1 & 2 & 3 & 4 & 5 & 6 & 7 & 8 & 9 & 10 & 11 & 12 & 13 & 14 & 15 & 16 & 17 \\
\hline 2.1 .1 & & & & & 0.816 & & & & & & & & & & & & \\
\hline 2.1.2 & & & & & 0.688 & & & & & & & & & & & & \\
\hline 2.1 .3 & & & & & 0.689 & & & & & & & & & & & & \\
\hline 2.1.4 & & & & & & & & & & & & & & & & & \\
\hline 2.1 .5 & & & & & & 0.719 & & & & & & & & & & & \\
\hline
\end{tabular}


Table 20: Continued.

\begin{tabular}{|c|c|c|c|c|c|c|c|c|c|c|c|c|c|c|c|c|c|}
\hline \multirow{2}{*}{ CMHQ item } & \multicolumn{17}{|c|}{ Part I component } \\
\hline & 1 & 2 & 3 & 4 & 5 & 6 & 7 & 8 & 9 & 10 & 11 & 12 & 13 & 14 & 15 & 16 & 17 \\
\hline 2.1 .6 & & & & & & & & & 0.723 & & & & & & & & \\
\hline 2.1.7 & & & & & & & & & 0.607 & & & & & & & & \\
\hline 2.1 .8 & & & & & & 0.769 & & & & & & & & & & & \\
\hline 2.1 .9 & & & & & & & & & & 0.606 & & & & & & & \\
\hline 2.1 .10 & & 0.595 & & & & & & & & & & & & & & & \\
\hline 2.1.11 & & & & 0.771 & & & & & & & & & & & & & \\
\hline 2.1 .12 & & & & 0.758 & & & & & & & & & & & & & \\
\hline 2.1 .13 & & 0.564 & & & & & & & & & & & & & & & \\
\hline 2.1 .14 & & & & & & & & & & 0.793 & & & & & & & \\
\hline 2.1 .15 & & 0.585 & & & & & & & & & & & & & & & \\
\hline 2.1 .16 & & 0.604 & & & & & & & & & & & & & & & \\
\hline \multicolumn{18}{|l|}{2.1 .17} \\
\hline 2.1 .18 & & 0.792 & & & & & & & & & & & & & & & \\
\hline \multicolumn{18}{|l|}{2.1 .19} \\
\hline 2.1 .20 & & 0.794 & & & & & & & & & & & & & & & \\
\hline 2.1 .21 & & & & & & & 0.698 & & & & & & & & & & \\
\hline 2.1 .22 & & & & & & & 0.703 & & & & & & & & & & \\
\hline 2.1 .23 & & & & & & & 0.695 & & & & & & & & & & \\
\hline 2.1 .24 & & & 0.827 & & & & & & & & & & & & & & \\
\hline 2.1 .25 & & & 0.838 & & & & & & & & & & & & & & \\
\hline \multicolumn{18}{|l|}{2.1 .26} \\
\hline 2.1.27 & & & 0.607 & & & & & & & & & & & & & & \\
\hline 2.1 .28 & & & 0.620 & & & & & & & & & & & & & & \\
\hline 2.1 .29 & & & & & & & & 0.552 & & & & & & & & & \\
\hline 2.1 .30 & & & & & & & & 0.592 & & & & & & & & & \\
\hline 2.1 .31 & & & & & & & & 0.782 & & & & & & & & & \\
\hline 2.1 .32 & 0.742 & & & & & & & & & & & & & & & & \\
\hline 2.1 .33 & 0.808 & & & & & & & & & & & & & & & & \\
\hline 2.1.34 & 0.828 & & & & & & & & & & & & & & & & \\
\hline 2.1 .35 & 0.808 & & & & & & & & & & & & & & & & \\
\hline 2.1 .36 & 0.682 & & & & & & & & & & & & & & & & \\
\hline 2.1 .37 & 0.796 & & & & & & & & & & & & & & & & \\
\hline \multicolumn{18}{|l|}{2.1 .38} \\
\hline 2.1.39 & & & & & & 0.507 & & & & & & & & & & & \\
\hline 2.2 .1 & 0.872 & & & & & & & & & & & & & & & & \\
\hline 2.2 .2 & 0.900 & & & & & & & & & & & & & & & & \\
\hline 2.2 .3 & 0.799 & & & & & & & & & & & & & & & & \\
\hline 2.2 .4 & & & 0.772 & & & & & & & & & & & & & & \\
\hline 2.2 .5 & & 0.692 & & & & & & & & & & & & & & & \\
\hline 2.2 .6 & & 0.736 & & & & & & & & & & & & & & & \\
\hline 2.2.7 & & 0.681 & & & & & & & & & & & & & & & \\
\hline 2.2 .8 & & & 0.655 & & & & & & & & & & & & & & \\
\hline 2.2 .9 & & 0.602 & & & & & & & & & & & & & & & \\
\hline 2.2 .10 & & 0.567 & & & & & & & & & & & & & & & \\
\hline \multirow{2}{*}{ CMHQ item } & \multicolumn{17}{|c|}{ Part III component } \\
\hline & 1 & 2 & 3 & 4 & 5 & 6 & 7 & 8 & 9 & 10 & 11 & 12 & 13 & 14 & 15 & 16 & 17 \\
\hline 3.1 .1 & & & & & & & & & 0.679 & & & & & & & & \\
\hline 3.1 .2 & & 0.573 & & & & & & & & & & & & & & & 0.528 \\
\hline 3.1 .3 & & 0.675 & & & & & & & & & & & & & & & \\
\hline 3.1 .4 & & 0.654 & & & & & & & & & & & & & & & \\
\hline 3.1 .5 & & 0.636 & & & & & & & & & & & & & & & \\
\hline 3.1 .6 & & 0.679 & & & & & & & & & & & & & & & \\
\hline 3.1 .7 & & 0.548 & & & & & & & & & & & & & & & \\
\hline 3.1 .8 & & & & & & & & & & & & & & & & & \\
\hline 3.1 .9 & & & & & & & & & & & & & & & 0.776 & & \\
\hline 3.2 .10 & & & & & & & & & & & & & & & & & \\
\hline 3.1 .11 & & & & & & & & & & & & & & & & & \\
\hline 3.1 .12 & & & & & & & & & 0.718 & & & & & & & & \\
\hline 3.1 .13 & & & & & 0.855 & & & & & & & & & & & & \\
\hline
\end{tabular}


Table 20: Continued.

\begin{tabular}{|c|c|c|c|c|c|c|c|c|c|c|c|c|c|c|c|c|c|}
\hline \multirow{2}{*}{ CMHQ item } & \multicolumn{17}{|c|}{ Part I component } \\
\hline & 1 & 2 & 3 & 4 & 5 & 6 & 7 & 8 & 9 & 10 & 11 & 12 & 13 & 14 & 15 & 16 & 17 \\
\hline 3.1 .14 & & & & & 0.744 & & & & & & & & & & & & \\
\hline 3.1 .15 & & & & & 0.745 & & & & & & & & & & & & \\
\hline 3.1 .16 & & & & & & & & 0.605 & & & & & & & & & \\
\hline 3.1 .17 & & & & & & & & 0.723 & & & & & & & & & \\
\hline 3.1 .18 & & & & & & & & 0.546 & & & & & & & & & \\
\hline 3.1 .19 & & & & & & & & & & & & & & & & 0.724 & \\
\hline \multicolumn{18}{|l|}{3.1 .20} \\
\hline 3.1 .21 & & & & & & & 0.704 & & & & & & & & & & \\
\hline 3.1 .22 & & & & & & & 0.863 & & & & & & & & & & \\
\hline 3.1 .23 & & & & & & & 0.517 & & & & & & & & & & \\
\hline 3.1 .24 & & & & 0.727 & & & & & & & & & & & & & \\
\hline 3.1 .55 & & & & 0.748 & & & & & & & & & & & & & \\
\hline 3.1 .26 & & & & 0.748 & & & & & & & & & & & & & \\
\hline \multicolumn{18}{|l|}{3.1 .27} \\
\hline \multicolumn{18}{|l|}{3.1 .28} \\
\hline 3.1 .29 & & & & & & 0.697 & & & & & & & & & & & \\
\hline 3.1 .30 & & & & & & & & & & & & & & 0.813 & & & \\
\hline 3.1 .31 & & & & & & & & & & & & & & 0.743 & & & \\
\hline 3.1 .32 & & & & & & & & & & & 0.788 & & & & & & \\
\hline 3.1 .33 & & & & & & & & & & & 0.793 & & & & & & \\
\hline 3.1.34 & & & 0.750 & & & & & & & & & & & & & & \\
\hline 3.1 .35 & & & 0.694 & & & & & & & & & & & & & & \\
\hline 3.1 .36 & & & 0.704 & & & & & & & & & & & & & & \\
\hline \multicolumn{18}{|l|}{3.1 .37} \\
\hline 3.1 .38 & & & 0.506 & & & & & & & & & & & & & & \\
\hline 3.1 .39 & & & 0.509 & & & & & & & & & & & & & & \\
\hline 3.1 .40 & & & & & & & & & & & & & 0.724 & & & & \\
\hline \multicolumn{18}{|l|}{3.1 .41} \\
\hline 3.1 .42 & & & & & & & & & & & & 0.676 & & & & & \\
\hline \multicolumn{18}{|l|}{3.1 .43} \\
\hline 3.1 .44 & 0.673 & & & & & & & & & & & & & & & & \\
\hline 3.1 .45 & 0.700 & & & & & & & & & & & & & & & & \\
\hline 3.1 .46 & 0.798 & & & & & & & & & & & & & & & & \\
\hline 3.1 .47 & 0.566 & & & & & & & & & & & & & & & & \\
\hline 3.1 .48 & & & & & & & & & & & & 0.614 & & & & & \\
\hline 3.1 .49 & 0.510 & & & & & & & & & & & & & & & & \\
\hline 3.1 .50 & & & & & & & & & & & & & & & & & 0.540 \\
\hline 3.1 .51 & 0.584 & & & & & & & & & & & & & & & & \\
\hline \multicolumn{18}{|l|}{3.1 .52} \\
\hline 3.1 .53 & 0.509 & & & & & & & & & & & & & & & & \\
\hline 3.1 .54 & & & & & & & & & & & & 0.608 & & & & & \\
\hline 3.1 .55 & & & & & & & & 0.537 & & & & & & & & & \\
\hline \multicolumn{18}{|l|}{3.1 .56} \\
\hline 3.1 .57 & 0.562 & & & & & & & & & & & & & & & & \\
\hline 3.1 .58 & & & & & & 0.545 & & & & & & & & & & & \\
\hline 3.1 .59 & & & & & & 0.724 & & & & & & & & & & & \\
\hline 3.1 .60 & & & & & & & & & & & & & 0.731 & & & & \\
\hline 3.1 .61 & & & & & & & & & & 0.735 & & & & & & & \\
\hline 3.1 .62 & & & & & & & & & & 0.661 & & & & & & & \\
\hline 3.2 .1 & 0.743 & & & & & & & & & & & & & & & & \\
\hline 3.2 .2 & 0.792 & & & & & & & & & & & & & & & & \\
\hline 3.2 .3 & & & 0.650 & & & & & & & & & & & & & & \\
\hline 3.2 .4 & & & & & & & & & & & & & & & & & \\
\hline 3.2 .5 & & & 0.589 & & & & & & & & & & & & & & \\
\hline 3.2 .6 & & & & & & 0.805 & & & & & & & & & & & \\
\hline 3.2 .7 & & & & & & & & & & & & & & & & & \\
\hline 3.2 .8 & & & & & 0.766 & & & & & & & & & & & & \\
\hline 3.2 .9 & & & & & & & & & & & & & & & & & \\
\hline 3.2 .10 & & & & & & & & & & & & & & & & & \\
\hline
\end{tabular}


TABle 20: Continued.

\begin{tabular}{|c|c|c|c|c|c|c|c|c|c|c|c|c|c|c|c|c|c|}
\hline \multirow{2}{*}{ CMHQ item } & \multicolumn{17}{|c|}{ Part I component } \\
\hline & 1 & 2 & 3 & 4 & 5 & 6 & 7 & 8 & 9 & 10 & 11 & 12 & 13 & 14 & 15 & 16 & 17 \\
\hline 3.2 .11 & 0.584 & & & & & & & & & & & & & & & & \\
\hline 3.2 .12 & & & & & 0.665 & & & & & & & & & & & & \\
\hline 3.2 .13 & & 0.700 & & & & & & & & & & & & & & & \\
\hline 3.2 .14 & & 0.778 & & & & & & & & & & & & & & & \\
\hline 3.2 .15 & & & & & & & & & & & & & & & & & \\
\hline 3.2 .16 & & & 0.639 & & & & & & & & & & & & & & \\
\hline 3.2.17 & & & & & & & & & & & & & & & & & \\
\hline 3.2 .18 & & & & & & & & & & & & & & & & & \\
\hline 3.2 .19 & & & & 0.664 & & & & & & & & & & & & & \\
\hline 3.2 .20 & & & & 0.744 & & & & & & & & & & & & & \\
\hline 3.3.2.1 & & & & & 0.753 & & & & & & & & & & & & \\
\hline 3.3.2.2 & & & & 0.548 & & & & & & & & & & & & & \\
\hline 3.3.2.3 & & & & & 0.810 & & & & & & & & & & & & \\
\hline 3.3.2.4 & & & & & 0.591 & & & & & & & & & & & & \\
\hline 3.3.2.5 & & 0.675 & & & & & & & & & & & & & & & \\
\hline 3.3.2.6 & 0.638 & & & & & & & & & & & & & & & & \\
\hline 3.3.2.7 & & & & & & & & & & & & & & & & & \\
\hline 3.3.2.8 & & 0.629 & & & & & & & & & & & & & & & \\
\hline 3.3.2.9 & 0.521 & & & & & & & & & & & & & & & & \\
\hline 3.3 .2 .10 & & 0.805 & & & & & & & & & & & & & & & \\
\hline 3.3 .2 .11 & & 0.763 & & & & & & & & & & & & & & & \\
\hline 3.3.2.12 & & & & 0.624 & & & & & & & & & & & & & \\
\hline 3.3.2.13 & & & & 0.791 & & & & & & & & & & & & & \\
\hline 3.3 .2 .14 & & & & 0.699 & & & & & & & & & & & & & \\
\hline 3.3.2.15 & 0.782 & & & & & & & & & & & & & & & & \\
\hline 3.3 .2 .16 & 0.735 & & & & & & & & & & & & & & & & \\
\hline 3.3.2.17 & & & 0.801 & & & & & & & & & & & & & & \\
\hline 3.3 .2 .18 & & & 0.660 & & & & & & & & & & & & & & \\
\hline 3.3.2.19 & & & 0.622 & & & & & & & & & & & & & & \\
\hline 3.3.2.20 & & & 0.870 & & & & & & & & & & & & & & \\
\hline
\end{tabular}

Extraction method: principal component analysis. Rotation method: varimax with Kaiser normalization.

TABLE 21: Extraction of factors.

\begin{tabular}{lcc}
\hline CMHQ part 1: pain description & CMHQ part 2: aggravating and relieving factors & CMHQ part 3: accompanying symptoms \\
\hline FAC1.1F1CentralHead & FAC 2.1F1Mental & FAC 3.1F1Liver-Qi\&Fire \\
FAC 1.1F2WholeHead & FAC 2.1F2Food & FAC 3.1F2Eye \\
FAC 1.1F3LateralHead & FAC 2.1F3WeatherChange & FAC 3.1F3BoneJointWind \\
FAC 1.3F1RhythmHeadache & FAC 2.1F4NoFood\&Drink & FAC 3.1F4PoorDigestion \\
FAC 1.3F2ExplosiveNotDull & FAC 2.1F5MentalStrain & FAC 3.1F5LiverSpleenFire \\
FAC 1.3F3SharpHeadache & FAC 2.1F6MuscularStrain & FAC 3.1F6YinDeficiency \\
FAC 1.3F4TightHeadache & FAC 2.1F7Oil\&Spicy & FAC 3.1F7LiverAttackStomach \\
FAC 1.3F7DistendingHeadache & FAC 2.1F8WindDamp & FAC 3.1F8ENT \\
FAC 1.3F8EmptyHeadache & FAC 2.1F9PhysicalStrain & FAC 3.1F9LightSound \\
FAC 1.5F1LateOfDay & FAC 2.1F10Alcohol-DragCigar & FAC 2.2F1Rest \\
FAC 1.5F2BothEnd & FAC 2.2F2PhysicalStimulation & FAC 3.1F11Constipation \\
FAC 1.5F3AllDay & FAC 2.2F3EatingRelated & FAC 3.1F12BloodDeficiency \\
& & FAC 3.1F13YangDeficiency \\
& & FAC 3.1F14SpleenDeficienyOfBowel \\
Included: $n=12$ & Included: $n=13$ & FAC 3.1F16Tinnitus \\
\hline
\end{tabular}

*: In this table, "FAC" is the abbreviation of "factor," whereas the numbers 1.X after it indicate their section number. For instance, FAC1.6F1 denotes the extracted first factor of Table 11, which summarised items of forehead, back of the head, and top of the head. 
TABLE 22: Results of the cluster analysis.

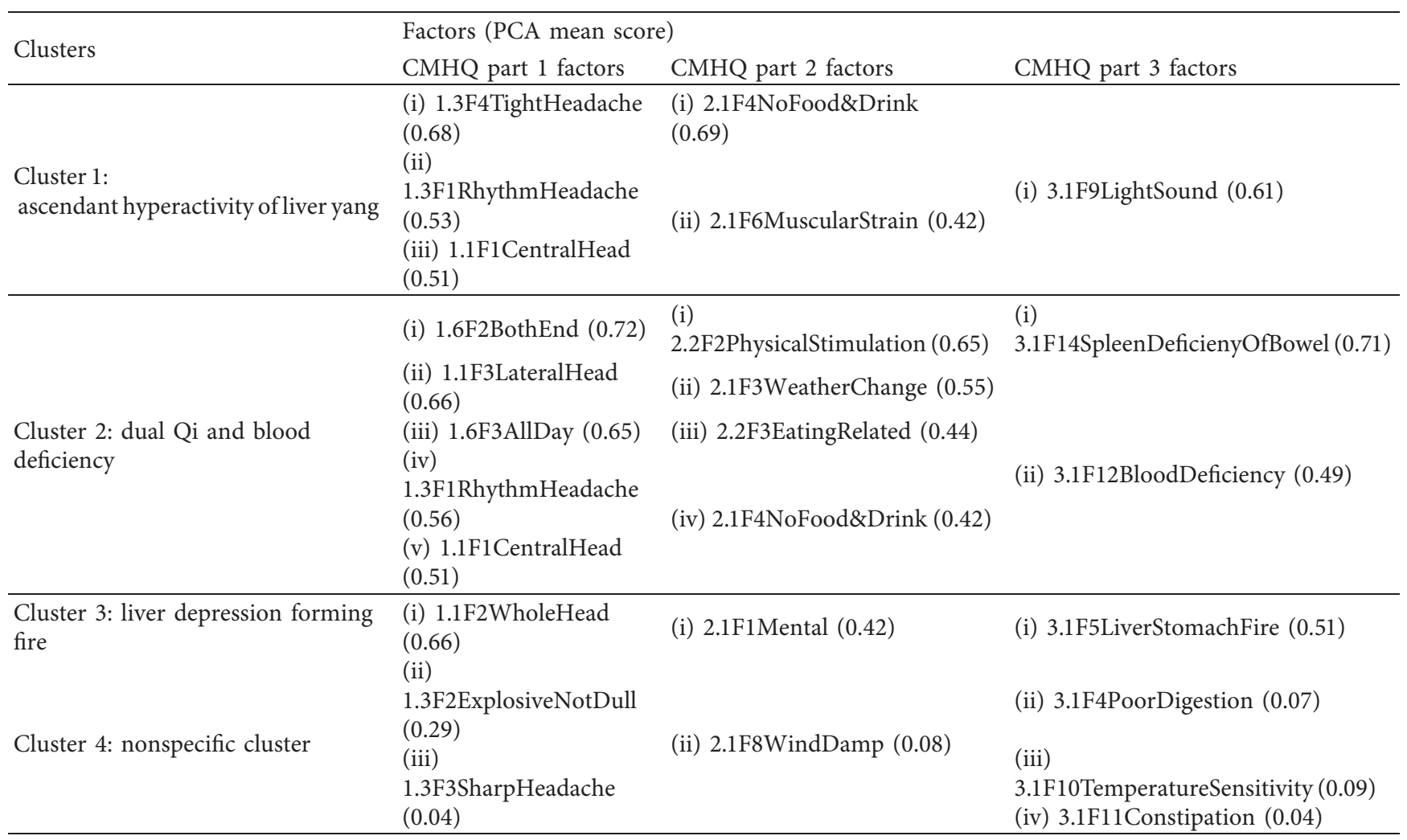

${ }^{*}$ : this table reports the results of the TwoStep cluster analyses. Computed from the TwoStep cluster algorithm, mean scores of extracted factors that exceeded value 0.4 are listed for clusters 1,2 , and 3 . The cutoff of 0.4 was determined as those clusters being considered to be clinically relevant.

TABLE 23: Group comparisons on MIDAS, PSS, and TTH subtypes between Asian and Non-Asian participants.

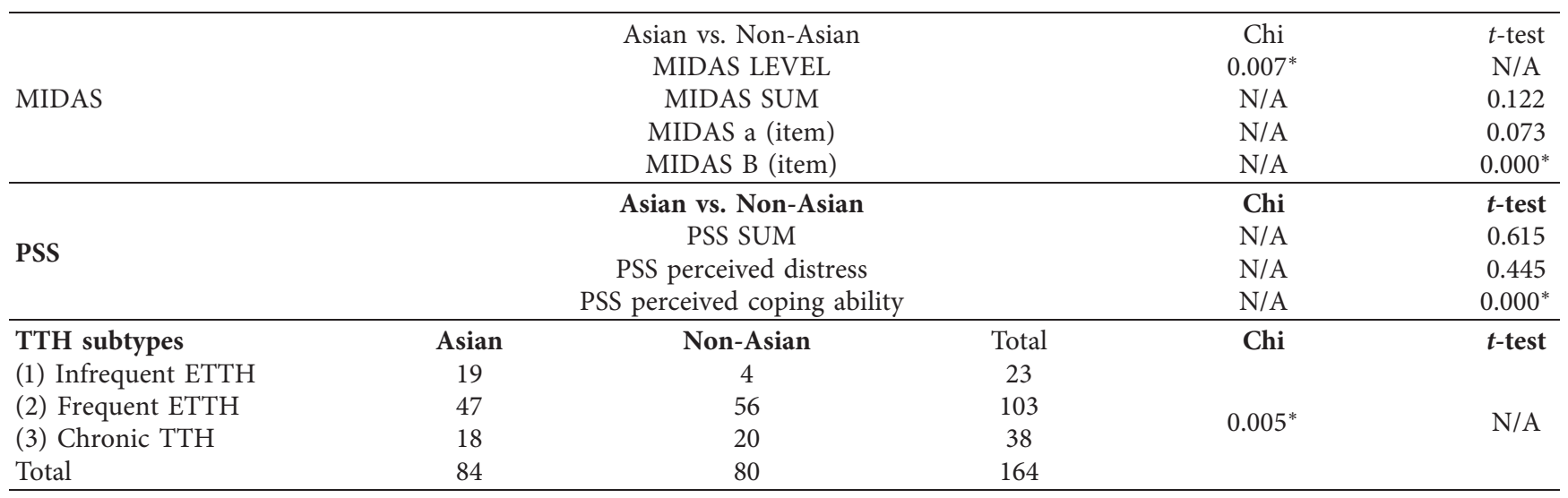

*: the mean difference is significant at the 0.05 level.

longitudinal cohort approaches to evaluate the stability of the identified CM patterns over time and to assess the effect of interventions.

\section{Conclusions}

This study provides new and critical information for determining the symptom patterns of TTH. The finding will contribute to the subgroup or pattern classification and guide targeted intervention design, including acupuncture, for future clinical practice and research. Future studies with a large sample size will identify other patterns in addition to those reported in the current study (Tables 6-23)

\section{Abbreviations}

ANOVA: One way analysis of variance CIRS: Cumulative Illness Rating Scale CM: $\quad$ Chinese medicine 
CMHQ: Chinese Medicine Headache Questionnaire

CTTH: Chronic tension-type headache

ETTH: Episodic tension-type headache

ICHD-II: Headache Society TTH Diagnostic Criteria (2nd edition)

IHS: International Headache Society

MIDAS: Migraine disability assessment test

PCA: $\quad$ Principal component analysis

PSS: $\quad$ Perceived Stress Scale

SD: $\quad$ Standard deviation

TCM: $\quad$ Traditional Chinese medicine

TTH: $\quad$ Tension-type headache

WMH- World Mental Health Composite International CIDI: Diagnostic Interview.

\section{Appendix}

\section{A. Chinese Medicine Headache Questionnaire (CMHQ)}

Please tick the listed items that best describe your headache and other symptoms you experienced over the last 3 months.

\section{Part I: Pain Description}

\section{Part II: Aggravating and Relieving Factors}

Part III: Accompanying Symptoms

\section{Part IV: Other Conditions}

\section{B. Rotated Component Matrix for CMHQ Factor Extraction}

\section{Extraction of Factors}

\section{Results of the Cluster Analysis}

\section{E. Group Comparisons on MIDAS, PSS, and TTH Subtypes between Asian and Non- Asian Participants}

\section{Data Availability}

The datasets used and/or analysed during the current study are available from the corresponding author on reasonable request.

\section{Ethical Approval}

The study was approved by the College Human Ethics Advisory Network (CHEAN) of Science Engineering and
Health, RMIT University (protocol approval number: BSEHAPP 10-11 HAO) and subsequently ratified by collaboration sites. Participation to the study was on a voluntary basis. All data were anonymous.

\section{Consent}

All participants were provided information explaining the purpose of the study and informed consent was obtained from them before inclusion.

\section{Disclosure}

The authors have submitted a draft version of the manuscript to Research Square previously. The current manuscript is our updated version for submission, which is different from the preprint on Research Square https://www. researchsquare.com/article/rs-10234/v1.

\section{Conflicts of Interest}

The authors declare that they have no conflicts of interest.

\section{Acknowledgments}

The authors would like to thank Prof. Albrecht Molsberger, Dr. Fayyaz Ahmed, Prof. Robert Helme, Prof. Stephen Gibson, Prof. Jiang Zhu, Prof. Lixing Lao, Prof. Paul Martin, Prof. John Reece, Prof. Jiying Zhou, and Dr. Jerusa Alecrim for expertise advice on the CMHQ development and survey investigation. The authors are grateful for expert opinions provided by Drs. Meaghan Coyle, Yuan Di, Lin Dong, David Lu, Yanyi Wang, and Claire Zhang to facilitate CM pattern identification. This work was supported by the Xinglin Academic Scientific Research Program of Chengdu University of Traditional Chinese Medicine (grant no. BSH2018020) and the National Health and Medical Research Council (NHMRC) Australia, Combined Electroacupuncture and Cognitive Behavioural Therapy for Tension-type Headache: A Randomised Controlled Trial (grant no. 555414).

\section{References}

[1] J. Olesen, D. Dodick, A. Ducros, S. Evers, M. First, and P. Goadsby, "Headache Classification Committee of the International Headache Society (IHS)The International Classification of Headache Disorders, 3rd edition (ICHD-3)," Cephalalgia, vol. 38, 2018.

[2] T. R. Vos, B. Barber, A. Bell, S. Bertozzi-Villa, and I. Biryukov, "Global, regional, and national incidence, prevalence, and years lived with disability for 301 acute and chronic diseases and injuries in 188 countries, 1990-2013: a systematic analysis for the Global Burden of Disease Study 2013," The Lancet, vol. 386, pp. 743-800, 2015.

[3] R. Jensen, "Diagnosis, epidemiology, and impact of tensiontype headache," Current Pain and Headache Reports, vol. 7, no. 6, pp. 455-459, 2003.

[4] M. E. Bigal and R. B. Lipton, "Tension-type headache: classification and diagnosis," Current Pain and Headache Reports, vol. 9, no. 6, pp. 423-429, 2005. 
[5] M. E. Lenaerts and L. C. Newman, "Tension-type headache," in Wolff's Headache and Other Head Pain, S. D. Siberstein, R. B. Lipton, and D. W. Dodick, Eds., pp. 293-314, Oxford University Press, New York, NY, USA, 2008.

[6] I. Devlin, "Headache in general practice," in Headache, Orofacial Pain and Bruxism, P. Selvaratnam, K. Niere, and M. Zuluaga, Eds., Churchill Livingstone, Edinburgh, Scotland, pp. 3-11, 2009.

[7] L. Mueller, "Tension-type, the forgotten headache. How to recognize this common but undertreated condition," Postgraduate Medicine, vol. 111, no. 4, pp. 25-50, 2002.

[8] R. Zivadinov, K. Willheim, D. Sepic-Grahovac et al., "Migraine and tension-type headache in Croatia: a populationbased survey of precipitating factors," Cephalalgia, vol. 23, no. 5, pp. 336-343, 2003.

[9] X. Li, J. Zhou, G. Tan, Y. Wang, L. Ran, and L. Chen, "Clinical characteristics of tension-type headache in the neurological clinic of a university hospital in China," Neurological Sciences, vol. 33, no. 2, pp. 283-287, 2012.

[10] X. Hao, C. C. Xue, L. Dong, and Z. Zheng, "Factors associated with conflicting findings on acupuncture for tension-type headache: qualitative and quantitative analyses," Journal of Alternative and Complementary Medicine, vol. 19, no. 4, pp. 285-297, 2013.

[11] G. G. Zhang, W. Lee, B. Bausell, L. Lao, B. Handwerger, and B. Berman, "Variability in the traditional Chinese medicine (TCM) diagnoses and herbal prescriptions provided by three TCM practitioners for 40 patients with rheumatoid arthritis," Journal of Alternative and Complementary Medicine, vol. 11, no. 3, pp. 415-421, 2005.

[12] J. W. Lance and P. J. Goadsby, Mechanism and Management of Headache, Elsevier/Butterworth Heinemann, Philadelphia, 7th ed. edition, 2005.

[13] R. Jensen and P. Torelli, "Treatment of tension-type headache," in Handbook of Clinical Neurology, F. Boller, M. J. Aminoff, and D. F. Swaab, Eds., Elsevier, Amsterdam, Netherlands, pp. 377-386, 2010.

[14] P. Martin, "Psychological management," in Headache, Orofacial Pain and Bruxism, P. Selvaratnam, K. Niere, and M. Zuluaga, Eds., Churchill Livingstone, Edinburgh, Scotland, pp. 277-288, 2009.

[15] E. L. H. Spierings, A. H. Ranke, and P. C. Honkoop, "Precipitating and aggravating factors of migraine versus tensiontype headache," Headache: The Journal of Head and Face Pain, vol. 41, no. 6, pp. 554-558, 2001.

[16] K. R. Merikangas, K. R. Merikangas, and J. Angst, "Psychopathology and headache syndromes in the community," Headache: The Journal of Head and Face Pain, vol. 34, no. 8, pp. S17-S22, 1994.

[17] J. P. Hatch, L. S. Schoenfeld, N. N. Boutros, E. Seleshi, P. J. Moore, and M. Cyr-Provost, "Anger and hostility in tension-type headache," Headache: The Journal of Head and Face Pain, vol. 31, no. 5, pp. 302-304, 1991.

[18] V. Ulrich, M. B. Russell, R. Jensen, and J. Olesen, "A comparison of tension-type headache in migraineurs and in nonmigraineurs: a population-based study," Pain, vol. 67, no. 2-3, pp. 501-506, 1996.

[19] A. I. Scher, R. B. Lipton, and W. F. Stewart, "Habitual snoring as a risk factor for chronic daily headache," Neurology, vol. 60, no. 8, pp. 1366-1368, 2003.

[20] C. Wöber, J. Holzhammer, J. Zeitlhofer, P. Wessely, and Ç. Wöber-Bingöl, "Trigger factors of migraine and tensiontype headache: experience and knowledge of the patients," The Journal of Headache and Pain, vol. 7, no. 4, pp. 188-195, 2006.
[21] J.-D. Lin, J.-S. Lin, L.-L. Chen, C.-H. Chang, Y.-C. Huang, and Y.-C. Su, "BCQs: a body constitution questionnaire to assess stasis in traditional Chinese medicine," European Journal of Integrative Medicine, vol. 4, no. 4, pp. e379-e391, 2012.

[22] C. Q. Guo and Y. S. Fan, Acupuncture and Moxibustion for Headache, People's Medical Publishing House, Beijing, China, 2010.

[23] R. B. Kelly, "Acupuncture for pain," American Family Physician, vol. 80, no. 5, pp. 481-484, 2009.

[24] D. H. Kim, "Evolution of acupuncture for pain management," Seminars in Integrative Medicine, vol. 2, no. 4, pp. 135-147, 2004.

[25] S. Carville, S. Padhi, T. Reason, M. Underwood, and G. Guideline Development, "Diagnosis and management of headaches in young people and adults: summary of NICE guidance," BMJ, vol. 345, no. sep19 1, p. e5765, 2012.

[26] K. Kennis, D. Kernick, and N. O’Flynn, "Diagnosis and management of headaches in young people and adults: NICE guideline," British Journal of General Practice, vol. 63, no. 613, pp. 443-445, 2013.

[27] K. Linde, G. Allais, B. Brinkhaus, E. Manheimer, A. Vickers, and A. R. White, "Acupuncture for tension-type headache," Cochrane Database of Systematic Reviews, vol. 1, p. CD007587, 2009.

[28] K. Linde, G. Allais, B. Brinkhaus et al., "Acupuncture for the prevention of tension-type headache," Cochrane Database of Systematic Reviews, vol. 4, p. CD007587, 2016.

[29] G. Maciocia, The Foundations of Chinese Medicine: A Comprehensive Text for Acupuncturists and Herbalists, Elsevier Churchill Livingstone, 1989.

[30] X. Hao, Development of Chinese Medicine Headache Questionnaire for Tension-type Headache, 2015, https://researchrepository. rmit.edu.au, $\mathrm{PhD}$ thesis.

[31] R. Q. Chen, C. M. Wong, K. J. Cao, and T. H. Lam, "An evidence-based validation of traditional Chinese medicine syndromes," Complementary Therapies in Medicine, vol. 18, no. 5, pp. 199-205, 2010.

[32] L. G. Portney, Foundations of Clinical Research: Applications to Practice, Prentice-Hall, Upper Saddle River, NJ, USA, 3rd ed. edition, 2008.

[33] R. Q. Chen, C. M. Wong, and T. H. Lam, "Construction of a traditional Chinese medicine syndrome-specific outcome measure: the Kidney Deficiency Syndrome Questionnaire (KDSQ)," BMC Complementary and Alternative Medicine, vol. 12, no. 1, p. 73, 2012.

[34] C. Lu, Q. Zha, A. Chang, Y. He, and A. Lu, "Pattern Differentiation in Traditional Chinese Medicine can help define specific indications for biomedical therapy in the treatment of rheumatoid arthritis," Journal of Alternative and Complementary Medicine, vol. 15, no. 9, pp. 1021-1025, 2009.

[35] G. Xiong, C. Virasakdi, A. Geater, Y. Zhang, M. Li, and S. Lerkiatbundit, "Factor analysis on symptoms and signs of chronic low-back pain based on Traditional Chinese Medicine theory," Journal of Alternative and Complementary Medicine, vol. 17, no. 1, pp. 51-55, 2011.

[36] Y.-J. Park, J.-S. Park, M.-Y. Kim, and Y.-B. Park, "Development of a valid and reliable phlegm pattern questionnaire," Journal of Alternative and Complementary Medicine, vol. 17, no. 9, pp. 851-858, 2011.

[37] B. K. Kang, T. Y. Park, J. A. Lee et al., "Reliability and validity of the Korean standard pattern identification for stroke (KSPI-Stroke) questionnaire," BMC Complementary and Alternative Medicine, vol. 12, p. 55, 2012. 
[38] K. Yao, L. Zhang, J. Wang, and J. Zhang, "Syndromes classification of the active stage of ankylosing spondylitis in traditional Chinese medicine by cluster Analysis of symptoms and signs data," in Information and Automation. ISIA 2010. Communications in Computer and Information Science, L. Qi, Ed., no. 86, Springer, Berlin, Germany, , pp. 657-663, 2011.

[39] X. Huang, Z. Li, W. Chen, M. Wang, and C. Zhang, "Cluster analysis on traditional Chinese medicine syndromes of chronic fatigue syndrome," Journal of Traditional and Complementary Medicine, vol. 21, no. 10, pp. 592-594, 2006.

[40] W. Liu, C. Wang, and Y. Wu, "Cluster Analysis on Chinese medicine syndromes of 260 rheumatoid arthritis patients," Journal of Traditional Chinese Medicine, vol. 57, no. 6, pp. 508-511, 2016.

[41] J. Olesen, "The international classification of headache disorders. 2nd edition (ICHD-II)," Revue Neurologique, vol. 161, no. 6-7, pp. 689-691, 2005.

[42] A. Straube and A. Andreou, "Primary headaches during lifespan," The Journal of Headache and Pain, vol. 20, no. 1, p. 35, 2019.

[43] W. F. Stewart, R. B. Lipton, A. J. Dowson, and J. Sawyer, "Development and testing of the migraine disability assessment (MIDAS) questionnaire to assess headache-related disability," Neurology, vol. 56, pp. s20-8, 2001.

[44] G. Georgoudis, A. Parasxou, and P. Chara, "Functional assessment in Greek tension-type headache sufferers: validity, reliability, responsiveness and psychometrics of the migraine disability assessment questionnaire (MIDAS)," British Journal of Medicine and Medical Research, vol. 56, no. 4, pp. 312-314, 2015.

[45] L. Grazzi, F. Andrasik, S. Usai, D. D’Amico, and G. Bussone, "Pharmacological behavioural treatment for children and adolescents with tension-type headache: preliminary data," Neurological Sciences, vol. 25, no. 3, pp. s270-s271, 2004.

[46] N. Karli, B. Baykan, M. Ertas et al., "Impact of sex hormonal changes on tension-type headache and migraine: a crosssectional population-based survey in 2,600 women," The Journal of Headache and Pain, vol. 13, no. 7, pp. 557-565, 2012.

[47] A. Zandifar, F. Asgari, F. Haghdoost et al., "Reliability and validity of the migraine disability assessment scale among migraine and tension type headache in Iranian patients," BioMed Research International, vol. 2014, no. 1, p. 978064, 2014.

[48] S. K1lıç, O. Derman, S. Aysun, and T. Kutluk, “The evaluation of tension-type headache, migraine and others type of headache in the adolescent by Midas measurement," European Journal of Paediatric Neurology, vol. 13, pp. s85-s86, 2009.

[49] S. Cohen, T. Kamarck, and R. Mermelstein, "A global measure of perceived stress," Journal of Health and Social Behavior, vol. 24, no. 4, pp. 385-396, 1983.

[50] S. Cohen and G. Williamson, "Perceived stress in a probability sample of the United States," in The Social Psychology of Health: Claremont Symposium on Applied Social Psychology, S. Spacapan and S. Oskamp, Eds., Sage, Newbury Park, CA, USA, 1988.

[51] B. S. Linn, M. W. Linn, and L. Gurel, "Cumulative illness rating scale," Journal of the American Geriatrics Society, vol. 16, no. 5, pp. 622-626, 1968.

[52] WHO, The World Health Organization World Mental Health Composite International Diagnostic Interview (WHO WMHCIDI), WHO, Geneva, Switzerland, 1990, https://www. brown.edu/academics/public-health/research/mens-healthinitiative/WHO-WMH-CIDI.

[53] I. N. C. SPSS, The SPSS TwoStep Cluster Component. A Scalable Component to Segment Your Customers More Effectively, SPSS Inc, Chicago, IL, USA, 2001.

[54] M. Y. Shih, J. W. Jheng, and L. F. Lai, "A two-step method for clustering mixed categroical and numeric data," Tamkang Journal of Science and Engineering, vol. 13, no. 1, pp. 11-19, 2010.

[55] J. F. Hair, W. C. Black, B. J. Babin, and R. E. Anderson, Multivariate Data Analysis, Prentice-Hall, Upper Saddle River, NJ, USA, 7th ed. edition, 2009.

[56] P. L. Hewitt, G. L. Flett, and S. W. Mosher, "The perceived stress scale: factor structure and relation to depression symptoms in a psychiatric sample," Journal of Psychopathology and Behavioral Assessment, vol. 14, no. 3, pp. 247-257, 1992.

[57] Q. Zhang, W. T. Zhang, J. J. Wei, X. B. Wang, and P. Liu, "Combined use of factor analysis and cluster analysis in classification of traditional Chinese medical syndromes in patients with posthepatitic cirrhosis," Journal of Chinese Integrative Medicine, vol. 3, no. 1, pp. 14-18, 2005.

[58] Q. Zhang, P. Liu, and W. T. Zhang, "An application of data mining in the research of TCM syndrome theories," Shanghai Journal of Traditional Chinese Medicine, vol. 40, no. 3, pp. 3-5, 2006.

[59] J. Liu, "Application and significance of cluster analysis in traditional Chinese medical research," Chinese Archives Of Traditional Chinese Medicine, vol. 22, no. 5, pp. 927-928, 2004.

[60] Z. M. Wang, G. Wang, J. C. Ji, and J. S. G., "Applied research of principal component analysis and cluster analysis in the early diagnosis of pancreatitis," Chinese Journal of New Clinical Medicine, vol. 6, p. 4, 2013.

[61] W. F. Velicer and J. L. Fava, "Affects of variable and subject sampling on factor pattern recovery," Psychological Methods, vol. 3, no. 2, pp. 231-251, 1998.

[62] C. Sun-Edelstein and A. Mauskop, "Complementary and alternative approaches to the treatment of tension-type headache," Current Pain and Headache Reports, vol. 16, no. 6, pp. 539-544, 2012.

[63] B. K. Rasmussen, "Migraine and tension-type headache in a general population: precipitating factors, female hormones, sleep pattern and relation to lifestyle," Pain, vol. 53, no. 1, pp. 65-72, 1993.

[64] D. Mitsikostas and A. Thomas, "Comorbidity of headache and depressive disorders," Cephalalgia, vol. 19, no. 4, pp. 211-217, 1999.

[65] F. Puca, S. Genco, M. Prudenzano et al., "Psychiatric comorbidity and psychosocial stress in patients with tensiontype headache from headache centers in Italy," Cephalalgia, vol. 19, no. 3, pp. 159-164, 1999.

[66] S. D. Siberstein and R. B. Lipton, Wolff's Headache and Other Head Pain, Oxford University Press, New York, NY, USA, 8th edition, 2008.

[67] H. A. van Suijlekom and F. Antonaci, "Cervicogenic headache," in Handbook of Headache, P. Martelletti and T. J. Steiner, Eds., Springer, Milano, Italy, pp. 471-482, 2011.

[68] J.-S. Lin, L.-L. Chen, J.-D. Lin et al., "BCQ: a body constitution questionnaire to assess Yin-Xu. Part ii: evaluation of reliability and validity," Forschende Komplementärmedizin/Research in Complementary Medicine, vol. 19, no. 6, pp. 285-292, 2012. 